\title{
Cure mechanisms of Diglycidyl Ether of Bisphenol A (DGEBA) Epoxy with
}

\section{Diethanolamine}

John D. McCoy*, Windy B. Ancipink, Caitlyn M. Clarkson, Jamie M. Kropka**, Mathias C. Celina**, Nicholas H. Giron**, Lebelo Hailesilassie, Narjes Fredj

New Mexico Institute of Mining and Technology, Socorro, NM

**Sandia National Laboratories, Albuquerque, NM

* Corresponding author

Keywords: Epoxy cure; tertiary amine - epoxide - hydroxyl reaction; glass transition

\begin{abstract}
:
When diethanolamine (DEA) is used as a curative for a DGEBA epoxy, a rapid "adduct-forming" reaction of epoxide with the secondary amine of DEA is followed by a slow "gelation" reaction of epoxide with hydroxyl and with other epoxide. Through an extensive review of previous investigations of simpler, but chemically similar, reactions, it is deduced that at low temperature the DGEBA/DEA gelation reaction is "activated" (shows a pronounced induction time, similar to autocatalytic behavior) by the tertiary amine in the adduct. At high temperature, the activated nature of the reaction disappears. The impact of this mechanism change on the kinetics of the gelation reaction, as resolved with differential scanning calorimetry, infrared spectroscopy, and isothermal microcalorimetry, is presented. It is shown that the kinetic characteristics of the gelationreaction of the DGEBA/DEA system are similar to other tertiary-amine activated epoxy reactions and consistent with the anionic polymerization model previously proposed for this class of materials. Principle results are the time-temperature-transformation diagram, the effective activation energy, and the upper stability temperature of the zwitterion
\end{abstract}


initiator of the activated gelation reaction. It is established that the rate of epoxide consumption cannot be generically represented as a function only of temperature and degree of epoxy conversion. The complex chemistry active in the material requires specific consideration of the dilute intermediates in the reaction sequence in order to define a model of the reaction kinetics applicable to all time-temperature cure histories.

\section{Introduction}

The use of diethanolamine (DEA) as a curative for the diglycidyl ether of bisphenol A (DGEBA) has a long history, having been used as the resin material for glass micro-balloon (GMB) filled composites since the mid-1950's. DGEBA/DEA/GMB has been particularly useful as a lightweight potting material in high performance aerospace applications [1-3]. The GMBs enable a reduction in the thermal expansion coefficient from that of the pure resin without the increase in glassy modulus associated with "hard" fillers like silica and alumina. This can be advantageous when stress associated with thermal fluctuations below the glass transition temperature, $T_{\mathrm{g}}$, is a concern. Primary design considerations in the development [1][4] of the DGEBA/DEA epoxy formulation were to have a low viscosity at the processing temperature and to prevent strong exothermic heating that can result in a "run-away" reaction for large mass batches. While the reason that this formulation meets the latter criterion may not have been understood at the time, we show that the unusual nature of the kinetics of the DGEBA/DEA reaction provides this benefit. Specifically, at high temperature and moderate to high extent of reaction, the polymerization rate decreases with increasing 
temperature such that self-heating associated with the exothermic reaction does not continue to accelerate the reaction kinetics.

Diethanolamine has three functional groups that are capable of reacting with the epoxide: a secondary amine and two hydroxyls. The secondary-amine reaction with epoxide is rapid, being accelerated by the presence of the high concentration of hydroxyls [5], and is complete within 30 min under processing conditions at $70^{\circ} \mathrm{C}$ [6]. This results in an adduct that undergoes further reaction, at a much slower rate, to form the crosslinked network. In previous literature on the DGEBA/DEA system, these two reaction regimes (fast and slow) have been denoted in various manners. For notational uniformity, the following nomenclature will be adopted. The rapid reaction between secondary amine and epoxide will be called the "adduct-forming reaction" instead of the previous terminology of "pre-reaction" or "clearing-reaction". All remaining reactions will be denoted by the single term "gelation-reaction" instead of the various "hydroxyl and epoxy reactions", "network-forming reaction", and "crosslinking reaction". The term "gelation-reaction" then embodies a number of sub-reactions, each with their own moreor-less complicated kinetics.

The gelation-reaction results in a glassy $\left(T_{\mathrm{g}} \sim 70^{\circ} \mathrm{C}\right)$, crosslinked network after 24 hrs when cured at $70^{\circ} \mathrm{C}$, and hence is considerably slower than the 30 min adductforming reaction. The chemical details of this reaction are less understood than that of the adduct-forming reaction, but it is clear that the reaction rate is not a simple function of temperature and epoxide reaction extent [6]. The complex kinetics is thought to result from the formation of a temperature sensitive transition state (or "activated") complex [710] as well as a diverse mixture of hydrogen bonded complexes that can either accelerate 
or inhibit the reaction [11]. The purpose of the present paper is to review the existing literature and to provide additional quantification of the gelation reaction that will increase the understanding of the polymerization mechanism as well as aid the prediction and optimization of the cure process as part of a comprehensive modeling effort of DGEBA/DEA.

The early development work for the DGEBA/DEA/GMB formulation, as is often the case, was largely trial and error [1-3]. Subsequent studies have been conducted to better understand the resulting material. Two important early studies of the polymerization kinetics of DGEBA/DEA were by Lundberg [12] in 1980 and by Adolf and Chambers [6] in 1997. Additional "in-house" studies of the kinetics have taken place since 1997 at Sandia National Laboratories (SNL) [13-16], some of which have been presented informally on the Web [17] and at conferences.

Lundberg [12] used three techniques to monitor the degree of cure. First, samples in curing ovens were periodically removed over the course of a year and the $T_{\mathrm{g}}$ measured. The $T_{\mathrm{g}}$ was found to steadily increase with cure time, even for the case of a cure temperature below $T_{\mathrm{g}}$. Second, the electrical dissipation factor and resistance were tracked and observed to change during cure. A plateau in these measurements with cure time was taken as an indication of the completion of the polymerization process. Finally, infrared (IR) spectra were measured and the epoxide $\left(913 \mathrm{~cm}^{-1}\right.$ band) and aliphatic ether $\left(1105 \mathrm{~cm}^{-1}\right.$ band $)$ conversions were tracked. A number of observations pertinent to the present study were made and will be described at the appropriate points. Adolf and Chambers [6] primarily relied on calorimetry in their study but verified their results with a few IR measurements. Their paper covered a wide range of properties 
and modeling of epoxies, with only a small section on reaction kinetics. Importantly, this was the first time that a kinetic equation was written for the DGEBA/DEA gelation reaction. They recognized (as had Lundberg) the roles of the two types of reactions in the cure. First is the rapid adduct-forming reaction of the DEA secondary amine that endcaps the DGEBA, making the DGEBA and DEA fully miscible. Second, is the slow gelation reaction that results in the cross-linking of the epoxy into a networked gel. A Kamal kinetics equation [18-20] was used to describe the gelation reaction:

$$
\frac{d \alpha}{d t}=\left(k_{1}+k_{2} \alpha^{m}\right)(1-\alpha)^{n}
$$

where $\alpha$ is the extent of reaction, and $k_{1}, k_{2}, m$, and $n$ can, in principle, be functions of temperature, although it is preferable that $m$ and $n$ be constants and that both $k_{1}$ and $k_{2}$ have Arrhenius dependencies on temperature with the same activation energy. For the case of the DGEBA/DEA gelation reaction, the temperature dependence of these parameters is more complicated [6]. Subsequent, unpublished attempts by Adolf and coworkers [21] refined, although did not simplify, this description. Measurements by our group have shown that these kinetic equations are only accurate for the gelation reaction over a narrow temperature range and only for isothermal cure. These new measurements will be discussed in the present paper.

Additional studies of DGEBA/DEA have been published sporadically. These include investigations of the gelation process [22-25], of the coefficient of thermal expansion [13], of mechanical properties [26-36], and of copolymers based on the DGEBA/DEA system [37]. 
The remainder of the paper is organized as follows. In section 2, the general background of the reaction chemistry of epoxy cured with alcohols in the presence of a tertiary amine initiator is presented. In section 3, experimental methods and materials are delineated. Our results are presented and discussed in section 4, and conclusions are drawn in section 5 .

\section{Reaction Mechanism}

The curing kinetics of DGEBA/DEA is more complicated than for most epoxy thermosets. There are at least three significant time-temperature regions involved, each with their own unique reaction behavior. First is the adduct-forming reaction between the secondary amine and epoxide groups. Second is the gelation-reaction at low temperature (below $70^{\circ} \mathrm{C}$ ), which is an "activated" reaction. Third is the gelation-reaction at high temperature (above $70^{\circ} \mathrm{C}$ ), where the activated nature of the reaction disappears.

Observationally, the two types of gelation pathways are distinguished by the presence, or absence, of a well-defined maximum in the rate of reaction as a function of time [as measured by differential scanning calorimetry (DSC)] during isothermal polymerization. At temperatures below $70^{\circ} \mathrm{C}$, there is a pronounced peak in the reaction rate with time, which is indicative of an activated (or strongly autocatalytic) process. At higher temperatures, the gelation reaction loses its autocatalytic character and lacks a strong peak in rate. From IR measurements it is difficult to distinguish between competing epoxy reactions during gelation and, in effect, only the extent of epoxide reaction $(\alpha)$ is tracked. This provides similar information on the reaction progression as obtained from DSC. 
Although the kinetics of DGEBA/DEA have only been lightly studied, similar reactions have been investigated in depth. The purpose of the present section is to review these studies. The adduct-forming reaction is the simplest of the DGEBA/DEA reactions. Because this reaction is not of primary interest in the present paper, only a few comments need be made regarding it. First, the reaction of the DEA amine with epoxide is known to be strongly catalyzed by the presence of the DEA-hydroxyls [5]. It has been observed that the epoxide-DEA reaction in a one-to-one (epoxide to amine) stoichiometry is "extremely vigorous" $[5,38,39]$. In practice, DGEBA/DEA is mixed in an apparently DEA-poor ratio and then relies on the epoxide-hydroxyl (both those on the DEA and those generated by the amine-epoxide reaction) and the epoxide-epoxide reactions to complete the curing process. Second, the immediate molecular environment of the epoxide group is found to be important to the reaction. Styrene oxide, for example, reacts only "modestly" with the amine in DEA and is a clear exception to the rapid reaction typical of epoxides such as phenyl glycidyl ether [39]. The change in reactivity results from the chemical structure difference between the monoepoxides, with styrene oxide having an epoxide group bonded directly to a phenyl group while phenyl glycidyl ether has an $-\mathrm{O}-\mathrm{CH}_{2}$ - linkage between phenyl and epoxide groups. This suggests that variation of epoxy resin could significantly affect the initial reaction rate with DEA. Phenyl glycidyl ether is the monoepoxide analog of the DGEBA studied here.

Epoxide reactions not involving either primary or secondary amines will now be considered. These reactions relate, either directly or indirectly, to the gelation-reaction in DGEBA/DEA. The simplest of these is the ring opening reaction of ethylene oxide. Ethylene oxide is stable until relatively high temperature [40] (as high as $380^{\circ} \mathrm{C}$ ). Above 
this temperature, the epoxide ring opens with a heat of reaction of $97.5 \mathrm{~kJ} / \mathrm{mole}$ in the vapor phase and then rapidly degrades into smaller molecules. Although this vapor phase, high temperature reaction is unimolecular, there is a distinct induction period associated with the ring opening. The activation energy [40] is reported to be 218 $\mathrm{kJ} /$ mole. Neat DGEBA, on the other hand, shows evidence for beginning decomposition (e.g., weight loss) at about $200^{\circ} \mathrm{C}$ (as seen in a Differential Thermal Analysis (DTA) scan at $2.5^{\circ} \mathrm{C} / \mathrm{min}$ [41]; a DSC scan at $20^{\circ} \mathrm{C} / \mathrm{min}$ [42]; and a Thermogravimetric Analysis (TGA) scan at $10^{\circ} \mathrm{C} / \mathrm{min}$ [43]). Consequently, investigations of DGEBA cure are necessarily restricted to temperatures below $200^{\circ} \mathrm{C}$. The total heat of reaction of epoxide groups over a broad range of epoxies is 100 to $118 \mathrm{~kJ} / \mathrm{mol}$ [8]. This is in good agreement with the ring opening of ethylene oxide, and shows a remarkable insensitivity to curing agent and molecular environment [8]. The activation energy, on the other hand, is quite sensitive to such details [10].

The presence of proton donors (e.g., alcohols) lowers the activation energy for ring opening considerably and increases the rate of reaction as compared to neat epoxide. The monoepoxide Cardura E at stoichiometric ratio with n-octanol has noticeable [38] reactivity at $150^{\circ} \mathrm{C}$, where half the epoxide reacts in $8 \mathrm{hrs}$. This epoxide-hydroxyl reaction exhibits an activation energy of only $45.6 \mathrm{~kJ} / \mathrm{mole}$ and shows no peak in the reaction rate with time (i.e., no autocatalytic behavior). A monoepoxide more similar to DGEBA is phenyl glycidyl ether. This molecule has a noticeable reaction with dipropylene glycol [9] at $200^{\circ} \mathrm{C}$, where half the epoxide reacts in $24 \mathrm{hrs}$. This epoxidehydroxyl reaction also shows no peak in the reaction rate with time. 
The simple, non-ionic addition reaction of epoxide with an alcohol is shown in Fig. 1. The reaction is irreversible since it involves the release of considerable energy in the opening of the epoxide ring. The alcohol can be the original short chain molecule or a hydroxyl group from a previous reaction. There could well be a dependence of the reaction rate on the degree of polymerization, $\mathrm{n}$, of the alcohol due to, for instance, differences in steric hindrance [38]. It should be noted that the concentration of hydroxyl groups is constant during the reaction and that the reaction rate is anticipated to be pseudo-first order in epoxide concentration. In addition to the obvious applicability of this reaction to bi-mixtures of epoxy and alcohol, this reaction, along with the similar epoxide-epoxide reaction, can be significant in mixtures such as DGEBA/DEA under certain conditions. While discerning this specific reaction mechanism in DGEBA/DEA

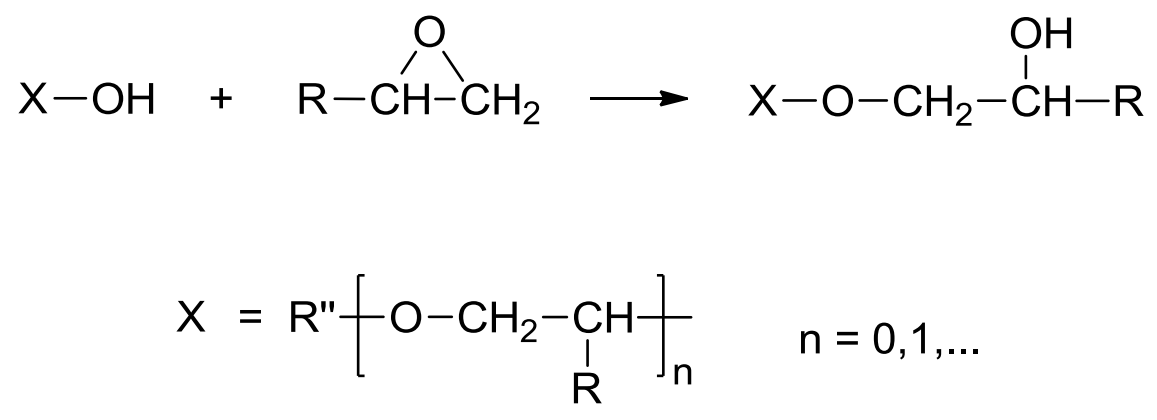

Fig 1. Non-ionic addition reaction of epoxide and hydroxyl. $R$ is remainder of epoxy molecule. R"' is rest of alcohol. Other symbols have usual meaning. is difficult, findings from studies of other epoxide-alcohol reactions $[5,9,10,38,44]$ provide a means to understand when this mechanism becomes dominant in

\section{DGEBA/DEA.}

The addition of a tertiary amine further lowers the temperature where ring opening is noticeable. For instance, ethylene oxide is found to react at $40^{\circ} \mathrm{C}$ with nbutanol (as well as with other alcohols) if triethylamine is present [10]. Moreover, the 
activation energy for the ring opening is estimated to be $48 \mathrm{~kJ} /$ mole for the overall reaction. Since the gelation reaction in DGEBA/DEA occurs in the presence of tertiary amines, the role of the tertiary amine in the polymerization process is important to understand. A detailed discussion of the chemistry of the reaction of epoxide in the presence of alcohol and tertiary amine will be presented in the following paragraphs.

An early study by Laird and Parker clarified and summarized much of the understanding $[5,9,39]$ of the reaction chemistry of epoxide with alcohols in the presence of tertiary amines [10]. Their study was of simple ethylene oxide, but its mechanism is the basis for understanding more complex epoxies $[8,11]$. Here we outline this mechanism, although the cited papers should be viewed for additional details.<smiles>[R19]N=[N+]=[R15]C1OC1[R]</smiles><smiles>[R]O[14CH2][NH2+]CC([R])[O-]</smiles>

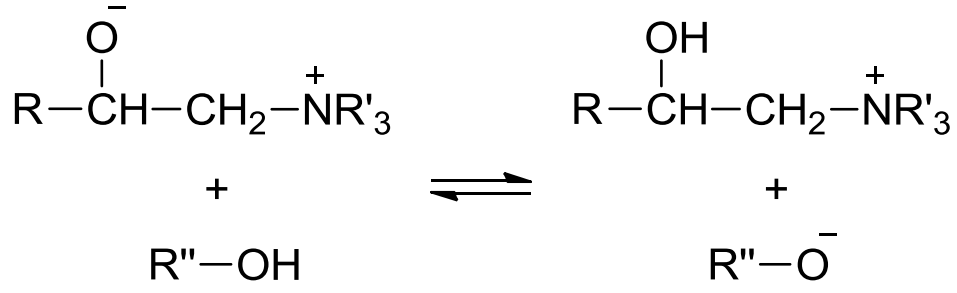

Fig 2. Initiation of chain reaction. $R$ is remainder of epoxy molecule. $R$ ' is the rest of the tertiary amine. All three R' are not required to be equivalent, for instance in the case of DEA that has reacted with an epoxide. R' is rest of alcohol. Other symbols have usual meaning. 
In the presence of a tertiary amine, an anionic chain growth polymerization is possible and consists of initiation, propagation and termination reactions. The initiation reaction sequence is shown in Fig. 2. The electron lone pair on the tertiary amine is a moderately strong Lewis base and forms a weak bond with one of the epoxide carbons while a hydroxyl forms a hydrogen bond with the epoxide oxygen. This three-molecule transition state (or activated) complex can then open the epoxide ring. The resulting ammonium zwitterion has a negatively charged oxygen while the nitrogen retains a positive charge. Proton transfer with an alcohol leads to a free alkoxide. The proton transfer is a reversible reaction but a large concentration of alcohol, such as in DGEBA/DEA, is expected to shift the equilibrium towards the free alkoxide and away from the zwitterion. The basic oxygen from either zwitterion or free alkoxide functions as an initiation site for chain growth. We will assume that the free alkoxide is the initiation site in the subsequent discussion, but the propagation reactions are similar for either zwitterion or free alkoxide initiated epoxy reaction. The use of an epoxide-tertiary amine zwitterion as an initiator in anionic polymerization of a wide range of monomers has been investigated [45] and illustrates its role in chain growth. It is important to note that the zwitterion/alkoxide species are reported to only be stable at low temperature (below $60^{\circ} \mathrm{C}$ for ethylene oxide [10]). For higher temperatures, these species are so dilute that they become unimportant to the reaction kinetics.

The propagation steps are shown in Fig. 3. The alkoxide formed from the alcohol can now react with a carbon on an epoxide ring, opening the ring and transferring the negative charge onto the oxygen of the newly opened ring. This negatively charged oxygen can then react with a carbon on another epoxide group in chain propagation or 
undergo proton transfer from a hydroxyl group. The proton transfer reaction results in a new hydroxyl being formed and, consequently, the hydroxyl concentration remains constant during the reaction. The donor hydroxyl becomes another reactive alkoxide.
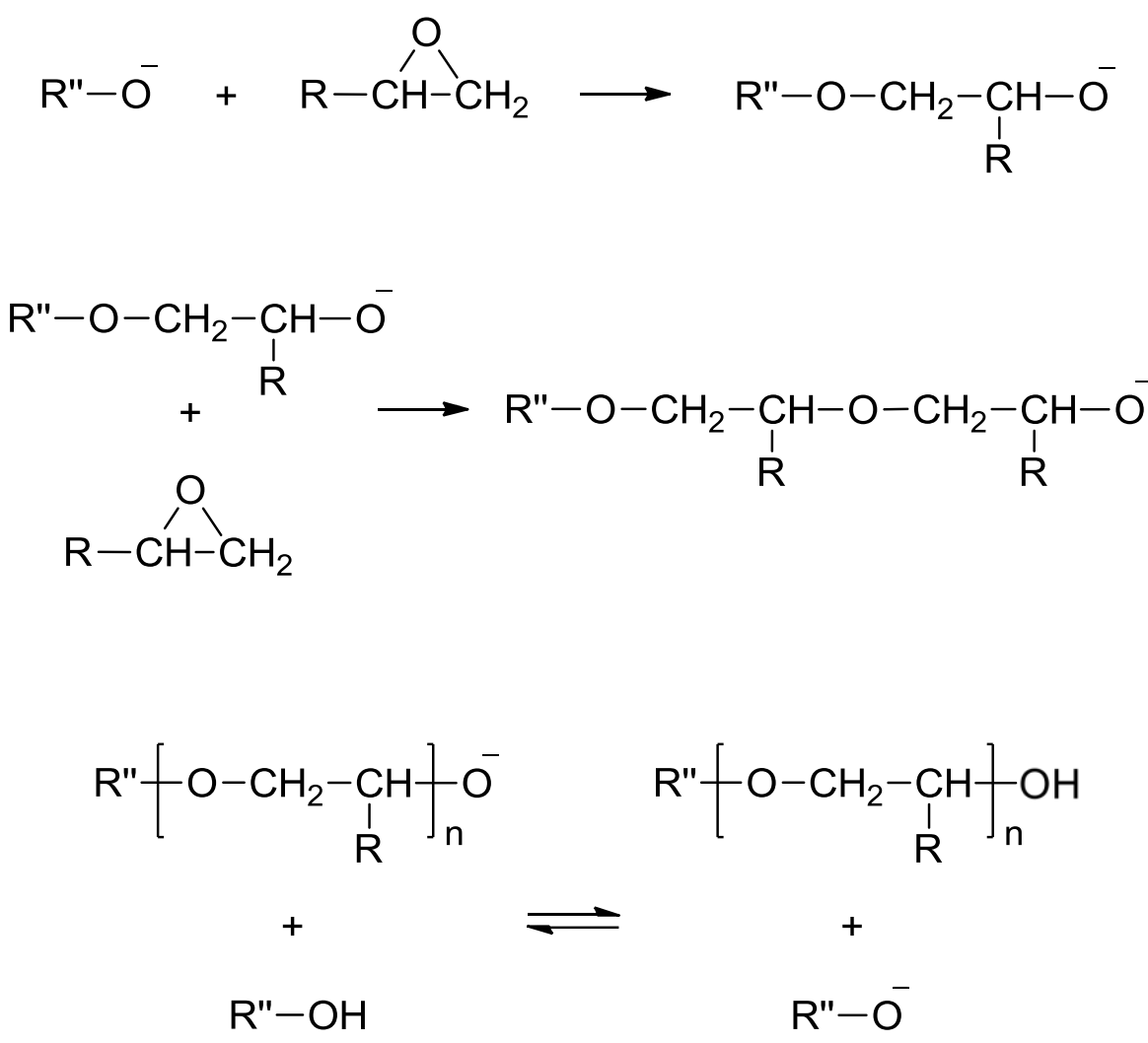

Fig 3. Propagation of chain reaction. $\mathrm{R}$ is remainder of epoxy molecule. $\mathrm{R}$ ' is rest of alcohol. Other symbols have usual meaning.

The termination reaction is shown in Fig. 4. The alkoxide reacts with a positively charged zwitterion tertiary-amine to form an ether bond and to free the (now neutral) amine. As is common in chain growth polymerization reactions, the relative rates of initiation, propagation, and termination steps determine not only the overall rate of reaction, but also the average chain length (or more properly in this case, the network structure). 


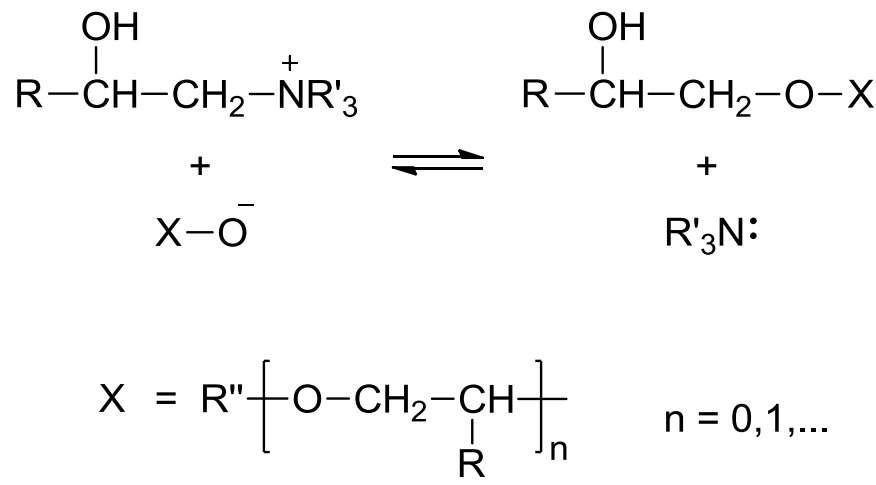

Fig 4. Termination of chain reaction. $\mathrm{R}$ is remainder of epoxy molecule. $\mathrm{R}$ ', is rest of the original alcohol. Other symbols have usual meaning.

The kinetics of the individual initiation, propagation, and termination reactions result in a complex dependence of the overall reaction rate on temperature, extent of reaction and history. The formation of the zwitterion/ alkoxide species is slow, resulting in a long induction period and a well-defined maximum in the reaction rate with time [8, 46]. Interestingly, the destabilization of the initiation species at high temperature reverts the polymerization process back to the simple non-ionic epoxide-hydroxyl addition reaction and the overall reaction rate is slower than expected from Arrhenius extrapolations from low temperature [47]. This, of course, will have implications on the temperature dependence of the DGEBA/DEA polymerization rate. Fernandez-Francos [7] has recently developed a detailed model of the kinetics of this reaction scheme, which builds on the previous work mentioned $[8,10]$ and references there in.

Other tertiary amines [45] and related nitrogen containing compounds have also been used for the initiation of epoxy cure. A study [46] of particular interest to the current project is the use of 4-(dimethylamino)pyridine (or DMAP) as an initiator for DGEBA (and in the absence of hydroxyl groups beyond the few normally found in DGEBA). The nitrogen in the pyridine is able to generate the zwitterion initiator without 
additional hydroxyl help. Indeed, the zwitterion appears to be stable to much higher temperature (at least $110^{\circ} \mathrm{C}$ ) than those of aliphatic amines, and gives an overall activation energy for the polymerization process of $62.4 \pm 0.5 \mathrm{~kJ} / \mathrm{mole}$ (for epoxide consumption). The maximum $T_{\mathrm{g}}$ (of $158^{\circ} \mathrm{C}$ ) from the cure process used in that study was observed for a mole ratio of DMAP to DGEBA groups of 0.08. Larger ratios resulted in smaller crosslink densities because of the "larger number of active chains competing for the epoxy groups" [46]. A similar study [47-49] was with DGEBA reacted with the alcohol 1,4-butanediol (BD) and with benzyl dimethylamine (BDMA) as the tertiary amine initiator. The DGEBA/BD/BDMA epoxy (mole ratio 1:1:0.05) shows activated behavior at $60^{\circ} \mathrm{C}$, but not at temperatures greater than $100^{\circ} \mathrm{C}$. These works demonstrate the polymerization of DGEBA in the presence of tertiary amine, either with or without the presence of significant hydroxyl group concentrations.

The DMAP and BDMA studies also illustrate the effect of tertiary amine structure on the stability of the anionic chain growth polymerization. The amine in DMAP is embedded in a conjugated ring structure that stabilizes the zwitterion without the further assistance of hydroxyl groups and generates zwitterions that are stable to high temperature. This is a behavior seen for other aromatic amines such as imidazoles [50]. On the other hand, amines such as triethylamine or BDMA both need assistance from hydroxyls to form a zwitterion and the generated zwitterion is only stable at low temperature with a fairly pronounced upper stability temperature (in the $60^{\circ} \mathrm{C}$ to $80^{\circ} \mathrm{C}$ region, depending on reagent details) [10]. The activation energy of the decomposition (i.e., termination reaction) of the zwitterion in weak amines similar to BDMA is about $160 \mathrm{~kJ} / \mathrm{mole}$ [10]. Since the activation energy of zwitterion formation is only $50 \mathrm{~kJ} / \mathrm{mole}$ 
[10], the much larger activation energy of decomposition changes the zwitterion from stable to unstable over a narrow temperature range. The consumption of epoxide in the DGEBA/BD/BDMA system mentioned above [47] is reported to have an effective activation energy of negative $29.4 \mathrm{~kJ} / \mathrm{mole}$ between $100^{\circ} \mathrm{C}$ and $180^{\circ} \mathrm{C}$. While the complexity of reaction possibilities in this mixture make it difficult to identify a single source of the apparent negative activation energy, the destabilization of the zwitterion initiating species is certain to be a contributing factor.

Another class of epoxy resins of interest is materials that contain tertiary amines as an integral part of the molecule itself (such as tetraglycidyl-diaminodiphenylmethane, TGDDM). These resins have many similarities to the DGEBA/DEA system studied here once the adduct forming reaction is complete. The tertiary amine initiated epoxidehydroxyl reaction is an important side reaction in these systems [11,51], and leads to the limited shelf life of TGDDM and related compounds (such as triglycidylaminophenol) [52].

The model compounds that were used to develop the kinetics scheme discussed above employed a free-standing tertiary amine of the form $\mathrm{R}_{3} \mathrm{~N}$ where the $\mathrm{R}$ 's were not reactive, such as $\mathrm{R}=-\mathrm{CH}_{2}-\mathrm{CH}_{3}$ for triethylamine. In the case of a DGEBA-DEA adduct, two of the R's are principal players in the chemical crosslinking process with $\mathrm{R}=-\mathrm{CH}_{2}$ $\mathrm{CH}_{2}-\mathrm{OH}$ and the third is the large DGEBA molecule. Initially, the small ethanol groups would leave the nitrogen relatively sterically unhindered. As the reaction proceeds and the ethanol groups become bonded to other DGEBA molecules, the amine becomes increasingly sterically hindered. This will eventually prevent the amine from engaging in zwitterion formation. The quantitative effect this has on the overall DGEBA/DEA 
reaction rate is difficult to assess since it is confounded with other factors that also affect reaction rate. The significance of this mechanism though, is illustrated by a study by Shechter and Wynstra [9] of reactions of tertiary amines with different degrees of steric hindrance.

While the above discussions have presented the role of alcohols and tertiary amines on the ring opening of epoxides, the relevance of the ether groups that result from the hydroxyl-epoxide and epoxide-epoxide reactions has not been addressed. Being weak Lewis bases, one might expect these polyethers to create a more favorable reaction environment for the ring opening process. However, such ether groups are not believed to act as catalysts $[7,8,10,38,39]$ for this reaction. This is, for instance, illustrated by the lack of reactivity of styrene oxide with dipropylene glycol at $100^{\circ} \mathrm{C}$ even after $8 \mathrm{hrs}$. Only when a tertiary amine is added does the reaction progress [39]. Of course, if the ether groups did catalyze the zwitterion formation, the increasing concentration of ether groups as the reaction progresses would contribute to the overall autocatalytic behavior. Because this is not believed to be the case, the dominant reason for the autocatalytic behavior is expected to be the slow buildup of anions resulting from activated trimolecular complexes of tertiary amine, hydroxyl and epoxide.

In summary, while the nature of the DGEBA/DEA adduct-forming reaction has been firmly established as a rapid secondary amine reaction accelerated by the DEA hydroxyls, the above literature review strongly implies that the gelation reaction involves a number of potential paths. The tertiary-amine activated reaction of hydroxyl and epoxide is usually a minor competing reaction in epoxides stoichiometrically cured with primary and secondary amines, even in the absence of reagents containing explicit 
hydroxyl groups. This reaction is possible because the opening of the epoxide group in an amine reaction results in a secondary or primary hydroxyl group in addition to the amine linkage. However, in the case of DGEBA/DEA, the hydroxyls are a principle crosslinking reactant. Once the secondary amine is consumed in the adduct forming reaction, the much slower hydroxyl-epoxide reaction [38] is catalyzed by the tertiary amine product of the adduct forming reaction through the mechanistic pathway outlined above. It is worth repeating that the anionic chain growth mechanism is a delicate sequence that can be disrupted by multiple factors. As already stated, the zwitterion initiating species becomes unstable at high temperatures and evolves as the reaction progresses. Impurities such as residual hydrolyzable chloride [9] from the manufacture of DGEBA [44, 53] and the presence of water and acid traces [8] can also strongly influence the reaction sequence. The dominant mechanistic path will depend on all of

these factors. And since the reaction mechanisms are difficult to distinguish chemically, dominant mechanisms must be inferred from measurements of the reaction rate alone. Throughout the remainder of this manuscript, the mechanistic understanding arrived at through the model studies reviewed will be used to interpret the complex kinetic behavior observed in the DGEBA/DEA system.

\section{Experimental Procedure}

\subsection{Materials and Sample Preparation}

The epoxy resin used in this study was EPON 828 (Momentive), a diglycidyl ether of bisphenol A (DGEBA). It has a mass per epoxide of 185 to $192 \mathrm{~g} / \mathrm{eq}$ and a mass density of $1.16 \mathrm{~g} / \mathrm{ml}$ at $25^{\circ} \mathrm{C}$. Its viscosity is 110 to 150 Poise at room temperature and, consequently, requires heating (to $70^{\circ} \mathrm{C}$ ) before mixing with the hardener. 
The curing agent, or hardener, employed was diethanolamine (DEA), which is a tri-functional reagent with the chemical formula $\mathrm{HN}\left(\mathrm{CH}_{2} \mathrm{CH}_{2} \mathrm{OH}\right)_{2}$. It has a molecular weight of $105.14 \mathrm{~g} / \mathrm{mole}$ and an epoxide equivalent weight of $35.05 \mathrm{~g} / \mathrm{eq}$. A stoichiometric mix of DGEBA:DEA is 1:0.187 parts by weight (pbw). In practice, an epoxide rich mix ratio is used (1:0.12 pbw). For the 1:0.12 case, the secondary amine hydrogen reacts quickly with the epoxide (within 30 min at $70^{\circ} \mathrm{C}$ ) while the remaining epoxide reacts slowly $\left(90 \%\right.$ reacted within 24 hours at $\left.70^{\circ} \mathrm{C}\right)$. This large separation of reactive timescales enables the study of these reactions individually.

The resin and hardener are heated for 1 hour before mixing (at $\left.70^{\circ} \mathrm{C}\right)$. The mixture is initially immiscible and, when hand mixed, results in an opaque liquid. As the secondary-amine reaction proceeds (forming the adduct), the solution clears and the mixture becomes fully miscible. This "clearing" takes place during a period of 15 to 30 minutes while the solution is periodically stirred and maintained at $70^{\circ} \mathrm{C}$ in a curing oven. Samples (roughly 70mg) to be tested in a Q2000 DSC (TA Instruments) are made in high-volume pans (TA Instruments) from the still warm mixture immediately after clearing. The high volume $(100 \mu \mathrm{l})$ DSC samples were used to amplify the heat flow signal, particularly in the long time tail of the reaction. Prior to filling, the pans were cleaned with acetone and oven dried to remove residual traces of oils that might be present on the pans since marked dewetting behavior of this epoxy was observed in untreated-pans. The sample pans were cooled to room temperature by placing on a room temperature steel block. Samples were then refrigerated $\left(-20^{\circ} \mathrm{C}\right)$ in sealed containers until use, typically for a few weeks or less. No significant difference in the measured heat flow signal is distinguished between freshly-made and refrigeration-stored samples. 
After the adduct-forming reaction, $21 \%$ of the total epoxide reactivity is consumed. If DEA-hydroxyls then preferentially react, upon their exhaustion $36 \%$ of the total epoxide reactivity will still remain unreacted. However, because additional hydroxyls are produced by the reaction and because epoxide-epoxide reactions are also possible, there is a potential for the epoxide to be fully consumed. It is sometimes assumed that these additional "backbone" hydroxyl groups generated during the reaction are more kinetically constrained $[38,54]$ than the DEA hydroxyls, and, consequently, react more slowly; however, we see no direct evidence of this. This point was discussed by Lundberg [12].

Contrary to expectations, a stoichiometric mix of DGEBA to DEA should not be (and is not) used as the sole material optimization criterion. Instead, all the requirements of the material must be considered. Obviously, one of these requirements is the final properties of the cured material. As in other tertiary-amine systems, the mix ratio can be adjusted through trial and error to maximize $T_{\mathrm{g}}$, which is often needed for a structural encapsulant or adhesive material. For the EPON 828/DEA case, the mix ratio of 1:0.12 generates [16] the material with the highest $T_{\mathrm{g}}$ for a given cure time at cure temperatures near $70^{\circ} \mathrm{C}$. In this case, the ratio of tertiary-amine to epoxide in the adduct is $27 \mathrm{~mol} \%$. This is considerably higher than the DGEBA: 4-(dimethylamine)pyridine (DMAP) cured system discussed above [46] which found that an $8 \%$ amine/epoxide ratio (assuming only the single aromatic $\mathrm{N}$ is active on each DMAP) maximized $T_{\mathrm{g}}$. The difference in amine/epoxide ratio is not surprising considering that DMAP is a stronger nucleophile than the DGEBA/DEA adduct. 


\subsection{DSC Methods}

A Q2000 DSC with a RCS90 refrigerated cooler (TA instruments) was employed in this study. It was primarily run in modulated mode (mDSC), which permitted observation of vitrification during the cure. All mDSC runs used a temperature modulation amplitude of $0.1^{\circ} \mathrm{C}$ and a period of $1 \mathrm{~min}$. An extended isothermal hold was run on the instrument to track the reaction progression and was followed by heat-coolheat temperature ramps for identification of the resulting glass transition temperature $\left(T_{\mathrm{g}}\right)$. The isothermal holds were for times of 24 to $72 \mathrm{hrs}$ for temperatures from $50^{\circ} \mathrm{C}$ to $110^{\circ} \mathrm{C}$. After the isothermal hold, the following thermal profile was performed: (1) quench to $25^{\circ} \mathrm{C}$, (2) heat at $10^{\circ} \mathrm{C} / \mathrm{min}$ to $130^{\circ} \mathrm{C}$, (3) hold isothermal at $130^{\circ} \mathrm{C}$ for $5 \mathrm{~min}$, (4) cool to $25^{\circ} \mathrm{C}$ at $10^{\circ} \mathrm{C} / \mathrm{min}$, (5) hold isothermal at $25^{\circ} \mathrm{C}$ for $5 \mathrm{~min}$, and then (5) heat at $10^{\circ} \mathrm{C} / \mathrm{min}$ to $130^{\circ} \mathrm{C}$. Midpoint $T_{\mathrm{g}}$ 's are reported from the second heating cycle. There was no significant exothermic reaction during the heat-cool-heat cycle, although enthalpic peaks indicative of physical aging were observed during the first heating cycle.

Because of the slow kinetics of the gelation reaction, the rate of heat generation during the isothermal hold is quite small and results in a limited signal-to-noise ratio. In particular, the peak heat flow for a reaction at $70^{\circ} \mathrm{C}$ for a $30 \mathrm{mg}$ (standard pan) sample is about $0.5 \mathrm{~mW}$. Variations of $\pm 2^{\circ} \mathrm{C}$ in the thermal environment that the instrument resides in during the extended runs result in slow variations of the heat flow baseline of \pm 0.04 $\mathrm{mW}$, hence $\pm 8 \%$ error. At lower temperature, the peak heat flow is lower and the fractional error is larger. Methods to address this limitation were employed.

The testing methodology evolved throughout the study. The best experiments were performed with the instrument (both DSC and cooler) in a thermally controlled 
chamber (held at $27^{\circ} \pm 1^{\circ} \mathrm{C}$ ) that cycled $\pm 1^{\circ} \mathrm{C}$ on approximately one minute intervals. This treatment kept the instrument, with its large thermal mass, isothermal to within a fraction of a degree. The DSC (with reference pan in place) was equilibrated for $250 \mathrm{~min}$ at test temperature before the sample was inserted (without stopping the run). This long equilibration time is necessary to bring the DSC components to operating temperature. Pronounced drift in heat flow was obvious for shorter equilibration times. Fully cured epoxy of about the same total heat capacity was used as the reference material in order to match the thermal response of the sample. Before being inserted into the already running DSC, the sample pan is heated to test temperature by placing it on a pre-heated steel block of large thermal mass. This avoids a "thermal shock" to the DSC cell that would result in the DSC needing to re-equilibrate. A clear local minimum (for $\mathrm{T}<70^{\circ} \mathrm{C}$ ) between the heat generated by the initial amine-epoxide coupling and the heat generated by the slower subsequent reactions suggests that any heat generated by the gelation reaction during the mixing/clearing process is minimal. Similarly, IR spectroscopy reveals a pronounced induction time behavior between the end of the adduct-forming and the beginning of the gelation reaction.

For temperatures below $70^{\circ} \mathrm{C}$, the reaction becomes diffusion limited in a postvitrification region. The reaction rate is sufficiently low in this region that it is difficult to study with DSC even with exacting methods. Thus, focus will be on the previtrification kinetics. A subsequent study is in progress addressing the diffusion-limited kinetics based on more sensitive microcalorimetry and near IR methods.

\subsection{Infrared Spectroscopy}


Infrared spectroscopic studies were performed using a Pike GladiATR with a Bruker Equinox 55 IR spectrometer for isothermal cures under laboratory atmospheric conditions [55]. A droplet of the cleared DGEBA/DEA mixture was deposited on the ATR crystal and sequential spectra acquired at pre-set temperatures. The diamond ATR crystal surface was cleaned with isopropanol between runs. Temperature control was independently validated to be within $\pm 1^{\circ} \mathrm{C}$. The IR spectra were averaged in the usual manner (i.e. acquisition of at least 16 spectra), baseline corrected (rubber band) and vector normalized using the established Bruker Opus spectral processing software. The relative changes in peak height for epoxy $\left(913 \mathrm{~cm}^{-1}\right)$ and polyether $\left(1112 \mathrm{~cm}^{-1}\right)$ were tracked without any further spectral deconvolution, despite some evidence of residual clearing reactions (amine addition) during the initial cure affecting the peak shape of the high wave number shoulder of the epoxy band, and some minor spectral drift over the timeframe of a kinetic run. There is some competition between native absorbance of the DEA in the $920 \mathrm{~cm}^{-1}$ epoxy neighborhood, which changes during the adduct-forming stage of cure, but the gelation kinetics can still be quantified for epoxy consumption and polyether formation yielding direct information on reaction rate development as conversion progresses. Band intensities were normalized between the peak heights of the initial adduct stage and a fully cured material (i.e. when no further changes in the epoxy/polyether band could be observed after extended time at $70^{\circ} \mathrm{C}$ ). This yielded a measure of relative conversion for the gelation kinetics. This mid-IR approach is sufficient to yield peak reactivity data (rate and time to max. rate) within the scope of this study, but we recognize that a rigorous IR based kinetic analysis would require some band deconvolution or near IR (NIR) approaches in which the epoxy band absorbance is 
better resolved. Note that in principle the early adduct-forming stage can also be quantified in the near IR, where the amine-hydrogen and epoxy groups have separate and easily accessible spectral signatures. NIR epoxy consumption in transmission mode offers excellent consumption kinetics and cure level assessments [56-58] and will be applied in future work.

\subsection{Isothermal Microcalorimetry}

Extended isothermal runs were performed using a TAM Air isothermal calorimeter $[59,60]$ (TA instruments). Samples were made from cleared mixtures and were from $2 \mathrm{~g}$ to $15 \mathrm{~g}$ in $20 \mathrm{~mL}$ glass vials. These were run following standard TA operating procedures against reference vials of dry sand to balance the heat capacity responses. Such large samples enhance the signal at long times permitting the reaction to be tracked at low temperatures for weeks to months. Temperatures ranged from $30^{\circ} \mathrm{C}$ to the instrument's limit of $90^{\circ} \mathrm{C}$.

\section{Results and Discussion}

\subsection{Adduct-Forming Reaction}

The initial adduct-forming reaction between the secondary amine group on the DEA and the DGEBA-epoxide group is rapid and scales in an Arrhenius manner with temperature. The reaction kinetics are relatively straightforward and have been fit to a Kamal equation by Adolf et al.[17] based on DSC data. In Fig. 5.A, these Sandia-legacy results are shown for the adduct-forming reaction. The rate of heat evolution during cure measured by DSC was integrated and normalized by a total heat of reaction of $129 \mathrm{~J} / \mathrm{g}$ to give the extent of reaction, $\alpha$, versus the logarithm of time. The curves can be shifted 
onto a single curve by multiplying the time scales by an Arrhenius factor $\exp \left(-E_{\mathrm{a}} / R T\right)$.

We reanalyzed the Adolf data and found $E_{\mathrm{a}}=68.8 \mathrm{~kJ} / \mathrm{mole}$, differing only slightly from

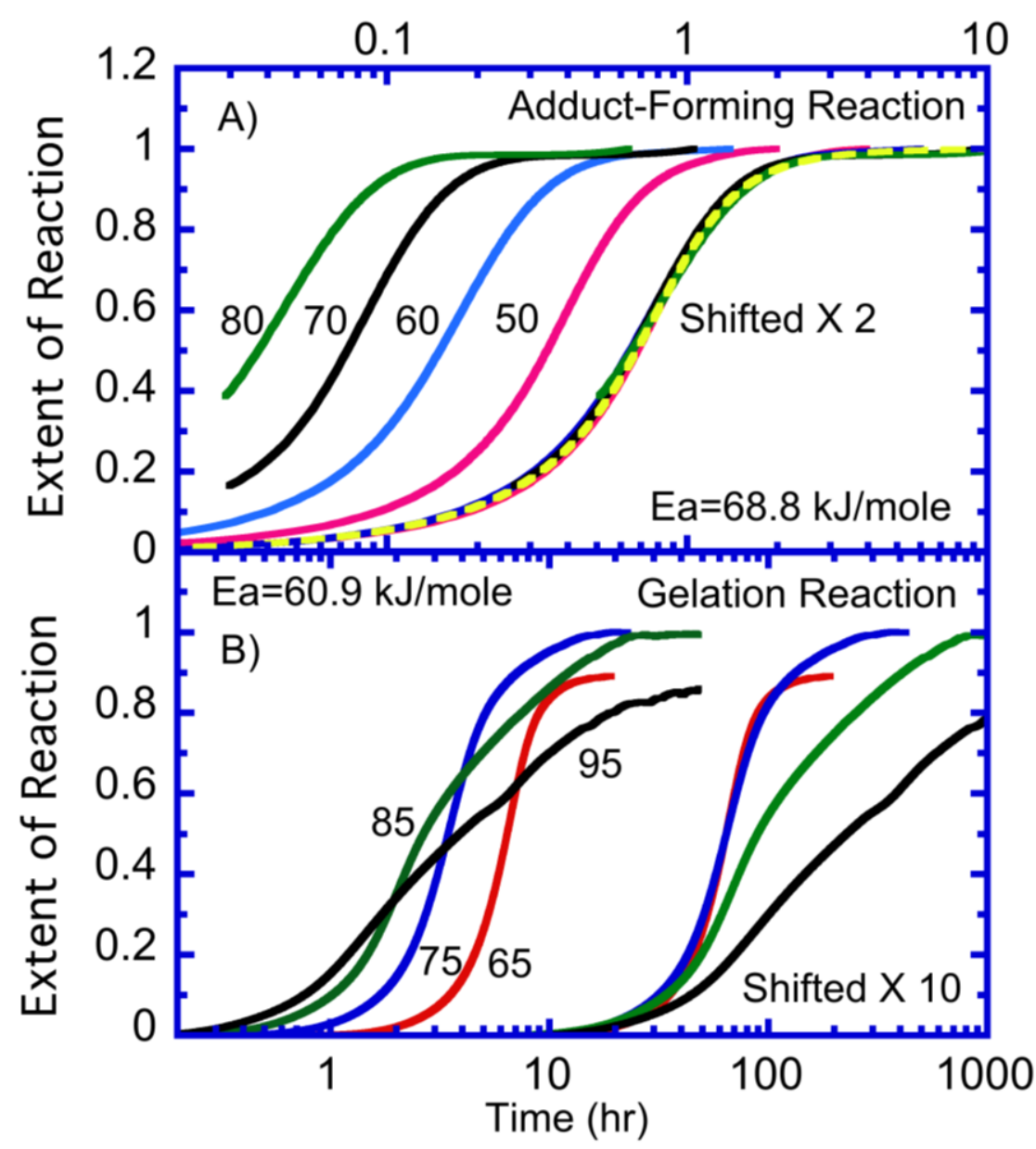

Fig 5. Extent of reaction versus time for both the adduct-forming and gelation reactions measured with DSC. A: Adduct-forming reaction at temperatures 50, 60, 70, $80^{\circ} \mathrm{C}$. Shifted using Arrhenius factor with $\mathrm{E}_{\mathrm{a}}=68.8 \mathrm{~kJ} / \mathrm{mole}$ and then shifted an additional factor of 2 . The prediction of the Kamal equation given in the text is a yellow dashed line on the shifted data. Missing early time data for $70^{\circ} \mathrm{C}$ and $80^{\circ} \mathrm{C}$ is the result of instrumental thermal equilibration. B: Gelation reaction at $65,75,85$, $95^{\circ} \mathrm{C}$. Shifted using Arrhenius factor with $\mathrm{E}_{\mathrm{a}}=60.9 \mathrm{~kJ} / \mathrm{mole}$ and then shifted an additional factor of 10 . This reaction does not follow a simple functional form.

the previously reported value of $69.0 \mathrm{~kJ} / \mathrm{mole}$. The kinetics are well described by the Kamal functional form with parameters as follows,

$$
\frac{d \alpha}{d t}=4 X 10^{8} s^{-1} \exp \left(-E_{a} / R T\right)\left[0.1+\alpha^{1.5}\right][1-\alpha]^{1.5}
$$


The superposition of results from all reaction temperatures and Eq. 4.1 is shown in Fig. 5.A (shifted by an additional factor of 2 for clarity).

It should be appreciated that because the secondary amine of DEA can only react once with an epoxide, the adduct-forming reaction does not result in crosslinking. Instead $21 \%$ of the epoxide groups are "end-capped" with the DEA. This initial coupling reaction leaves two DEA-hydroxyl groups and generates an additional hydroxyl from the epoxide oxygen. These three hydroxyls from each capping event (in addition to approximately $0.1 \mathrm{~mol}$ hydroxyls/mol epoxide in the original EPON 828 structure [53]) provide reactive sites for the slower gelation reaction. In addition, epoxide-epoxide reactions can, of course, contribute to gelation.

\subsection{Gelation Reaction}

The slower gelation reaction is clearly not simple (as shown in Fig. 5.B for temperatures between $65^{\circ} \mathrm{C}$ and $95^{\circ} \mathrm{C}$ ). The extent of reaction at a high temperature cannot be simply superimposed on a lower temperature by shifting the time. The shift factor applied to reaction time in the superposition attempt in Fig. 5.B employs the activation energy defined later in this paper, but clearly no choice would give adequate superposition. The data shown in this figure are from reanalysis of the original DSC data and differ slightly from that posted on the Sandia website [17] because of different selections of heat flow baselines.

Similar non-superimposable behavior can be seen in the IR measurements in Fig.

6. Here, the initial reaction rates seem plausible enough with the higher temperature $\left(80^{\circ} \mathrm{C}\right)$ reaction consuming epoxide more quickly than in the lower temperature case 
$\left(70^{\circ} \mathrm{C}\right)$. Half the epoxide is consumed in about $3 \mathrm{hrs}$ at $80^{\circ} \mathrm{C}$ while taking $4.5 \mathrm{hrs}$ at $70^{\circ} \mathrm{C}$. That is, an increase in rate by a factor of 1.5 . Assuming Arrhenius behavior, this implies an $E_{\mathrm{a}}$ of about $40 \mathrm{~kJ} / \mathrm{mol}$. On the other hand, the further consumption of epoxide

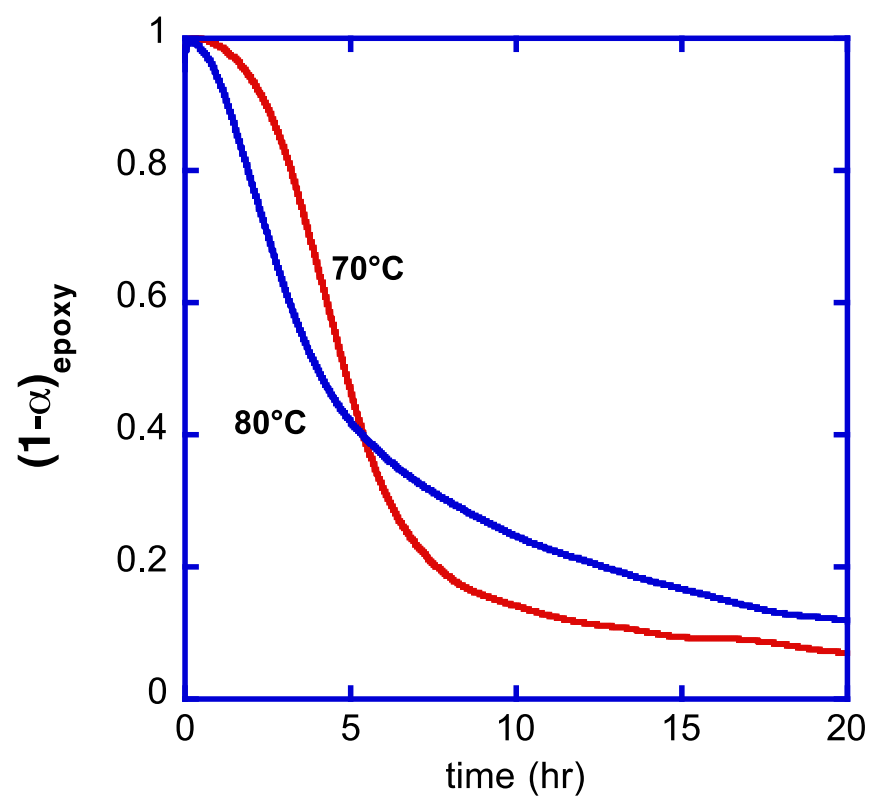

Fig. 6: Epoxy band consumption behavior at $913 \mathrm{~cm}^{-1}$ (IR data) showing the nonsuperimposability of the gelation reaction of DGEBA with DEA.

from $50 \%$ to $20 \%$ (remaining) is faster at $70^{\circ} \mathrm{C}$ than at $80^{\circ} \mathrm{C}$. This implies a non-physical negative activation energy, and consequently, suggests a mechanistic change in the reaction. [61].

Although the detailed explanation of this counterintuitive behavior is not fully understood, there are a number of contributing factors and putting the findings into the context of the reaction mechanisms discussed in section 2 helps to identify these factors and propose methodologies to further resolve the details. First, let us consider the decreased stability of the zwitterion initiation sites at high temperature that impacts the rate of the anionic step growth polymerization mechanism. At low temperature, the zwitterion/alkoxide propagating chains are stable with a very low termination rate even for high zwitterion concentrations $[8,46]$. Consequently, the concentration of alkoxide groups will increase as the reaction proceeds, at least until a maximum concentration is 
attained. At high temperature, on the other hand, the zwitterion/alkoxide termination reaction is non-negligible and competes with the formation of the initiating species. For an upper stability temperature of the zwitterion initiator of $\mathrm{T}=70 \mathrm{C}$ (see peak height behavior of Fig 8), this will keep the long time alkoxide concentration lower at $T=80^{\circ} \mathrm{C}$ than at $T=70^{\circ} \mathrm{C}$ and can account for slower epoxy consumption at $80^{\circ} \mathrm{C}$ in this stage of the reaction. Second, let us consider that even at the higher temperatures, at short times formation of zwitterion will exceed its elimination in the termination reaction because of the low concentration of zwitterion/alkoxide. Thus, at equivalent chain propagating species concentration (at both $T=80^{\circ} \mathrm{C}$ and $T=70^{\circ} \mathrm{C}$ ) the higher temperature will possess the faster polymerization rate. Exactly how long it takes for the "crossover" in reaction rate depends on the details of the competition between formation and termination of the chain propagating species at each temperature. Finally, a steric hindrance factor cannot be ignored [9]. Certainly, as the side groups on the amine nitrogen grow, it will be more difficult for the nitrogen to approach an epoxide carbon and will result in a slowdown in the formation of zwitterions. But relative changes in formation versus termination are more difficult to predict, especially over a range of temperatures. These ideas do not, of course, exhaust the possibilities of potential chemical mechanisms to explain the observed behavior, but they do provide a basis for further investigations to establish the underlying mechanism.

The consistency amongst measurement techniques and data sets is further demonstrated by Fig. 7. The DSC measurements, which track the rate of heat generation (proportional to the rate of the reaction assuming an equivalent amount of heat is released from each coupling reaction), are directly compared to the IR measurements, which track 
epoxide consumption, during an isothermal progression of the gelation reaction at $70^{\circ} \mathrm{C}$.

In order to make the comparison, time dependent IR results from the $913 \mathrm{~cm}^{-1}$ epoxide peak are fit to simple functions (hyperbolic tangent near the inflection point and power law near the long time tail). Numerical data are then extracted from the curve fits at

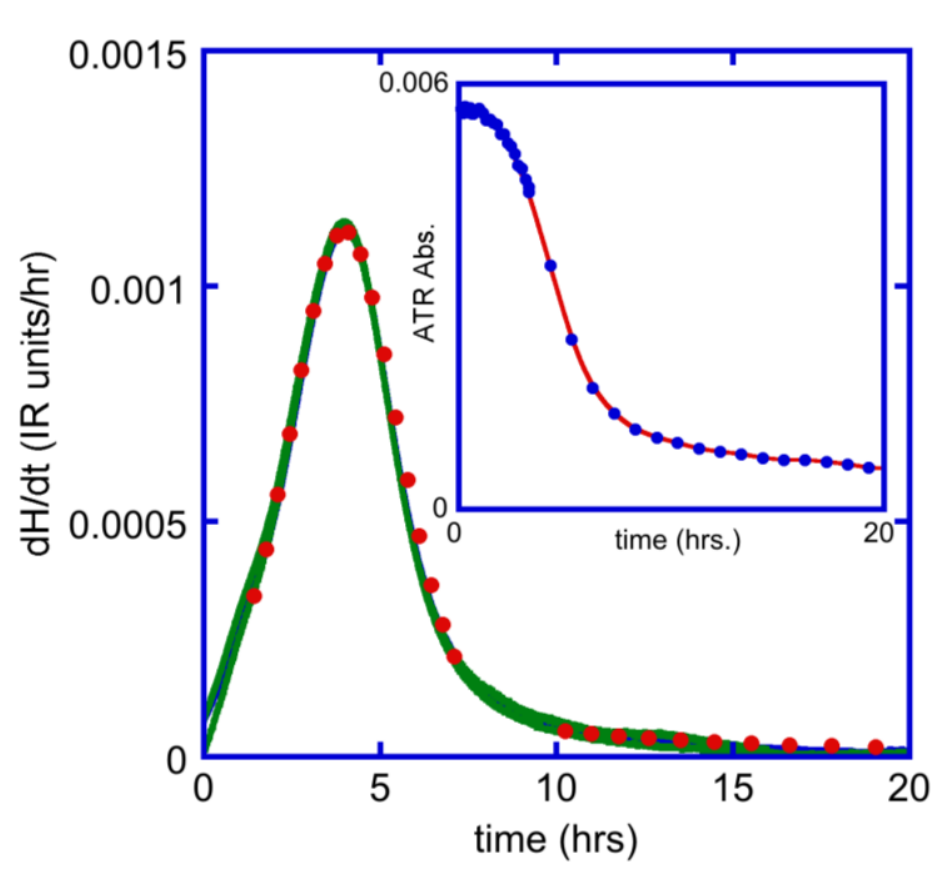

Fig 7. Rate of the gelation reaction at a cure temperature of $70^{\circ} \mathrm{C}$. The lines are DSC results scaled to IR units (These are indistinguishable from each other on this scale). Two of these DSC curves are $\mathrm{mDSC}$ and one is conventional DSC. The points are found from taking numerical derivatives of IR data tracking the epoxide peak $\left(913 \mathrm{~cm}^{-1}\right)$. The scaling factors differ slightly from DSC to DSC curve. The un-scaled peak heights were $0.0152 \pm 0.0005$ $\mathrm{W} / \mathrm{g}$. The time to the maximum rate of reaction is $3.98 \pm 0.01 \mathrm{hrs}$. The IR peak height as a function of time is shown in the inset.

closely spaced points and numerical derivatives taken. Only peak and long time tail regions were fit. The DSC data was then scaled to fit on the IR data. There are three DSC datasets plotted (one conventional and two modulated). The scaling was slightly different for the three measurement sets. The un-scaled DSC peak heights were $0.0152 \pm 0.0005 \mathrm{~W} / \mathrm{g}$ and the maximum rate deduced from IR measurements was 0.00111 IR absorbance/hr. The peak location was $3.98 \pm 0.01 \mathrm{hrs}$ for both IR and DSC runs. These results are also comparable to a previous study on this system by Adolf and Chambers [6] and demonstrate the equivalence of tracking the disappearance of epoxide absorption and heat produced during the reaction. The total heat produced during the gelation reaction in the first $24 \mathrm{hrs}$ is found to be $240 \pm 5 \mathrm{~J} / \mathrm{g}$ from the DSC measurements. Note that the local 
maximum observed in Fig. 7 indicates that the reaction rate initially accelerates with time, often referred to as an "autocatalytic", or "activated" response and is consistent with an increase in the zwitterion/alkoxide concentration in the mixture during the early stages of the reaction. Later, the reaction rate decelerates as the reacting species are depleted. The temperature dependence of this peak in reaction rate will be described in the following section.

\subsection{Variations of Peak Height and Peak Location}

If the gelation reaction followed simple reaction kinetics, then both peak height and peak time for the reaction rate (as shown in Fig 7) would follow an Arrhenius form and both quantities would exhibit the same activation energy. Consider the reaction equation

$$
\frac{d \alpha}{d t}=k(T) f(\alpha)
$$

where $f$ is a function of the epoxide extent of reaction, $\alpha$, alone and $k$ is an Arrhenius rate constant

$k(T)=k_{0} \exp \left(-E_{a} / R T\right)$.

Here $E_{\mathrm{a}}$ is an activation energy, $k_{\mathrm{o}}$ is a pre-exponential constant, $R$ is the ideal gas constant, and $T$ is absolute temperature. If time, $t$, is combined with $k(T)$ to give a normalized time $t^{*}$ (in a time-temperature superposition manner), a temperature independent form of the rate equation is deduced

$$
\frac{d \alpha}{d t^{*}}=f(\alpha)
$$


All signatures of the solution of this equation (such as the time and height of the peak) will be invariant in terms of $t^{*}$. This was shown to apply to the adduct-forming reaction in Fig. 5.A. Since $t^{*}$ varies as $k(T)$, the peak height and peak time will vary with respect to $T$ in an Arrhenius manner with a single activation energy. Consequently, an excellent way to assess if a reaction follows simple kinetics is to plot the logarithm of peak time

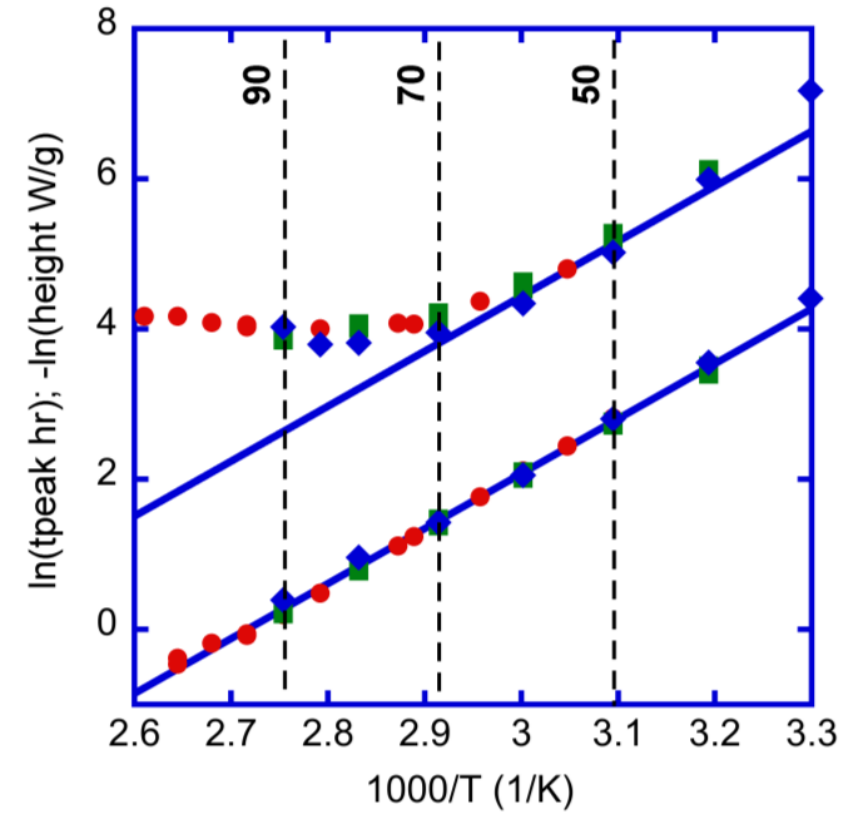

Fig 8. Analysis of maximum reactivity data for gelation reaction. Arrhenius Plot for time to maximum rate (lower points) and maximum reaction rate (upper points). Red circles are from DSC. Blue diamonds are from TAM Air micro-calorimetry. Green squares are from IR (peak heights at 913 $\mathrm{cm}^{-1}$ vertically shifted to overlap DSC). Lines have activation energies of $60.9 \mathrm{~kJ} / \mathrm{mole}$. The peak heights of the lowest two temperatures $\left(30^{\circ} \mathrm{C}\right.$ and $\left.40^{\circ} \mathrm{C}\right)$ are smaller than expected because vitrification occurs before the reaction peak is complete.

and of peak height versus inverse temperature. Of course, this analysis breaks down if the system vitrifies before the peak is fully developed.

In Fig. 8, the maximum reaction rate and the time that the maximum occurs are plotted against $1 / T$ for the gelation reaction. Consistent results are found from DSC, IR (derivatives of both epoxide and ether conversion data), and isothermal microcalorimetry. The peak times (lower set of points) follow an Arrhenius behavior to a high degree of accuracy. The resulting activation energy (given by the slope times the gas constant) is $60.9 \pm 0.5 \mathrm{~kJ} / \mathrm{mole}$ and suggests that Eqn. (4.2) may be appropriate to represent the overall kinetics of this reaction. On the other hand, the peak heights (upper set of points) only 
follow this Arrhenius form at low temperature. At temperatures above about $70^{\circ} \mathrm{C}$, the peak heights level off. Thus, a simple form of Eqn. (4.2) with a single activation energy is not sufficient to capture the kinetic behavior of DGEBA/DEA over the full temperature range examined, and more complicated empirical fits to the data are required [6].

It should be noted that empirical fits of an equation of form Eqn. (4.2) to isothermal reaction data may be of limited accuracy under more general conditions. For example, more complex thermal histories are expected to alter the overall reaction rate in a manner not captured by equations only trained to represent isothermal reaction data. In particular, let us consider performing a cure to a specific reaction extent, $\alpha$, at a given temperature, $T_{1}$, and then jumping to a different temperature, $T_{2}$. One might expect that the reaction rate at $T_{2}$ after this sequence would be the same as found for an isothermal cure at $T_{2}$ and an equivalent $\alpha$. Preliminary results of experiments of this type indicate that this expectation from a kinetics representation such as Eq. 4.2 does not hold. This finding may offer some insight into how the different potential polymerization reactions in the DGEBA/DEA material compete and is a topic of continuing research.

\subsection{Time-Temperature-Transformation}

In addition to the extent of cure, it is also important to understand the evolution in material physical properties as the reaction progresses. Here, we examine the cure times when the material gels and when the material vitrifies, as well as how the $T_{\mathrm{g}}$ of the material evolves during isothermal reaction. 
A primary benefit of the mDSC method $[62,63]$ is that it permits the "reversing heat capacity", $\operatorname{rev} C_{\mathrm{p}}$, to be monitored during the isotherm cure. This quantity is the ratio of the heat flow to rate of temperature variation:

$$
\text { rev } C_{P}=\frac{\text { Heat Flow Amplitude }}{\text { Heating Rate Amplitude }} X \text { Calibration Const. }
$$

where Heating Rate Amplitude is the maximum of $\mathrm{d} T / \mathrm{d} t$ per cycle, Heat Flow Amplitude is the maximum of $\mathrm{d} Q / \mathrm{d} t$ per cycle, $t$ is time and $Q$ is heat. This measures the thermal response over the course of a thermal cycle and, consequently, does not capture the nonreversing heat flow associated with the heat of reaction. Instead it measures something close to the traditional heat capacity. A detailed analysis of the $\operatorname{rev} C_{\mathrm{p}}$ is beyond the scope of the present paper. We use the $\operatorname{rev} C_{\mathrm{p}}$ as a tool to detect the vitrification of the epoxy during cure. While the epoxy is in the liquid/rubbery state, the $\operatorname{rev} C_{\mathrm{p}}$ remains relatively constant; however, at vitrification this quantity decreases. The onset of this decay is defined as the vitrification time, $t_{\mathrm{g}}$.

In Fig. 9, rev $C_{\mathrm{p}}$ curves for a range of isothermal cure temperatures are shown. The identification of $t_{\mathrm{g}}$ is indicated for a representative case by the arrow. In all cases, the revCp in the initial region is constant and drops by about $28 \%$ during vitrification. Although the detailed nature of the decay of $\operatorname{rev} C_{\mathrm{p}}$ depends on sample geometry and the balance between heat capacity and thermal conductivity, it is clear that it is a slow process extending over many hours. This finding is not surprising considering the lethargic rate of the chemistry-limited reaction and that, as the $T_{\mathrm{g}}$ of the material approaches the reaction temperature, diffusion will only further slow the reaction. Understanding how the material transitions from the equilibrium to the glassy state during the isothermal reaction is of continued interest. Many applications process 
materials such that vitrification occurs either before the polymerization reaction is complete or during the completion of the reaction. This type of processing embeds a "history" in the glassy polymer thermoset that influences its mechanical response. Remaining reaction potential in the material can also be accessed at later times if the conditions are such to facilitate further reaction. The capability to predict these material behaviors and their implications to stress in the material are continuing research interests.

The temperature behavior of the vitrification time is non-monotonic. As the cure temperature is increased from $50^{\circ} \mathrm{C}$ to $70^{\circ} \mathrm{C}, t_{\mathrm{g}}$ decreases. Thus the increase in reaction

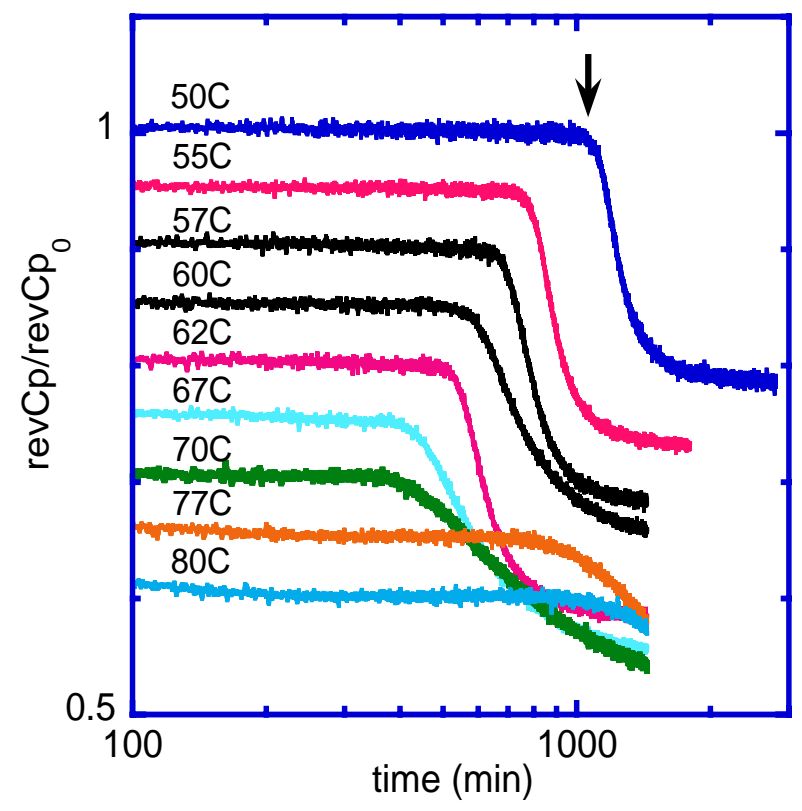

Fig 9. Reversing heat capacity for a range of isothermal cure temperatures showing the vitrification as a function of cure time. The arrow indicates the change in the heat capacity marking the transition from equilibrium to glass. The results for each temperature are shifted vertically for clarity.

rate from $50^{\circ} \mathrm{C}$ to $70^{\circ} \mathrm{C}$ outweighs the increase in reaction extent necessary to induce the vitrification. In this temperature region, the epoxy becomes glassy shortly after the peak in reaction rate. Above $70^{\circ} \mathrm{C}, t_{\mathrm{g}}$ increases with increasing temperature. Indeed, Lundberg [12] reported a $t_{\mathrm{g}}$ of several months for a cure temperature of $100^{\circ} \mathrm{C}$. The observed reversal in $t_{\mathrm{g}}$ behavior with temperature may simply be a consequence of the long-time reaction rate slowing down at high $T$ and that more total reaction is needed at 
high $T$ to induce vitrification. This slowing of the reaction rate is the natural consequence of the change in reaction mechanism resulting from the destabilization of the zwitterion complex at high temperature.

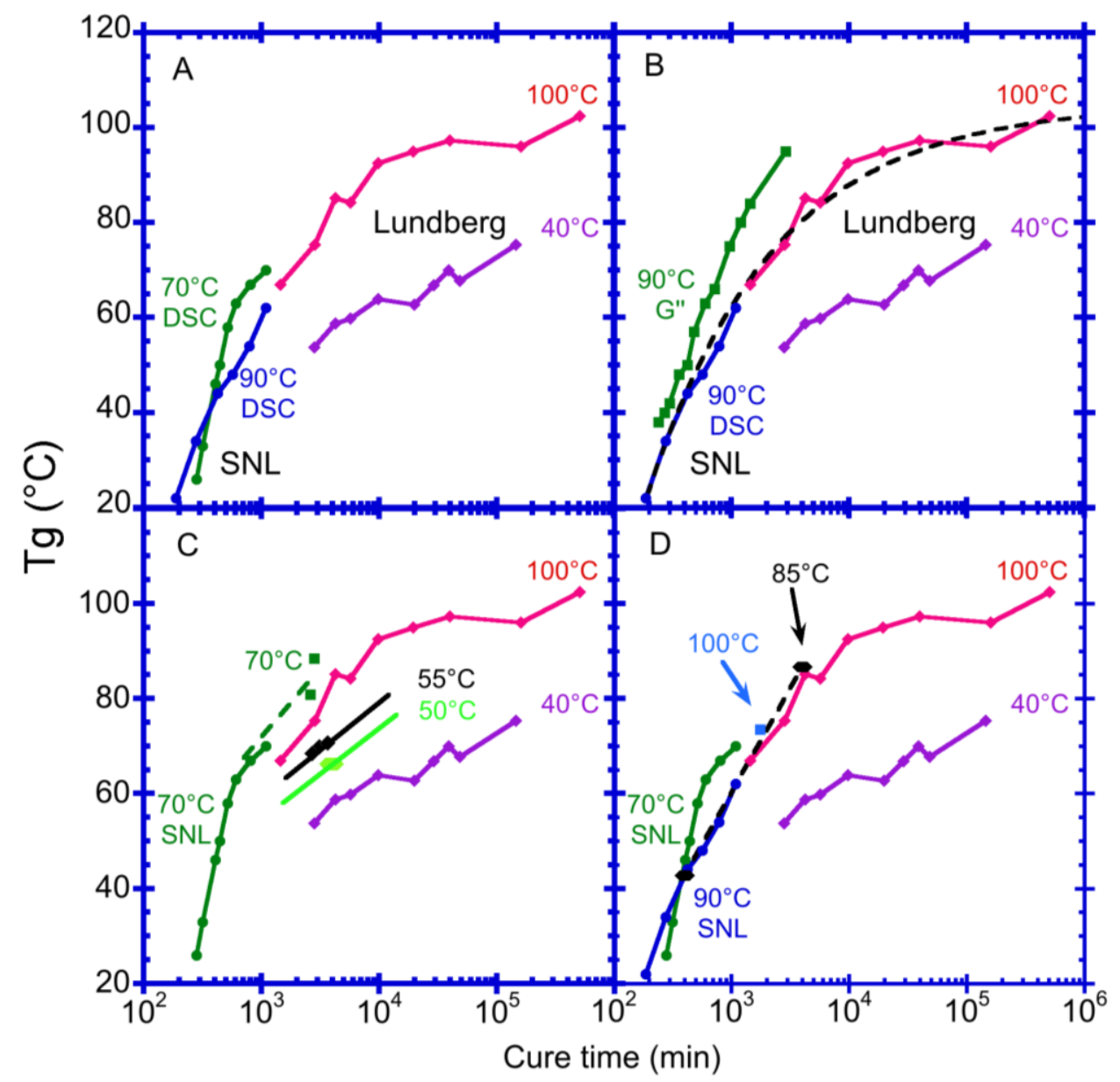

Fig 10. $T_{\mathrm{g}}$ as a function of cure time and cure temperature. $T_{\text {cure }}$ is indicated on the plots next to the individual lines. A) Sandia (SNL) Legacy DSC and Lundberg. B) SNL DSC, SNL Rheology and Lundberg. Dashed line is the curve fit discussed in text. C) SNL DSC, Lundberg and present study DSC for $T_{\text {cure }} \leq 70^{\circ} \mathrm{C}$. D) SNL DSC, Lundberg and present study DSC for $T_{\text {cure }} \geq 70^{\circ} \mathrm{C}$. Dashed line is for $85^{\circ} \mathrm{C}$ results (2 points).

In Fig. 10 glass transition temperatures at different cure times are shown. These results compliment the mDSC data of Fig. 9. At the vitrification-time, $t_{\mathrm{g}}$, found from the $\mathrm{mDSC}$, the $T_{\mathrm{g}}$ is the cure temperature. In Fig. 10 the $T_{\mathrm{g}}$ is found from a separate temperature ramp after a given cure time at a given cure temperature, $T_{\text {cure. }}$ The $T_{\mathrm{g}}$ is less 
than $T_{\text {cure }}$ for short cure time and is greater than $T_{\text {cure }}$ for long cure times. For example, for a $T_{\text {cure }}$ of $70^{\circ} \mathrm{C}$, a cure time of 300 min results in $T_{\mathrm{g}}=25^{\circ} \mathrm{C}$ while a cure time of 3000 min results in $T_{\mathrm{g}}=85^{\circ} \mathrm{C}$. In Fig. 10.A, Sandia (SNL) Legacy DSC results [17] are plotted along with Lundberg's long cure time results [12]. It appears that the SNL results merge into the $100 \mathrm{C}$ Lundberg results at times greater than $1000 \mathrm{~min}$. A more subtle feature is that the $T_{\text {cure }}=90^{\circ} \mathrm{C} T_{\mathrm{g}}$ 's are lower than the $T_{\text {cure }}=70^{\circ} \mathrm{C} T_{\mathrm{g}}$ 's for intermediate times (400 $\min <t<2000 \mathrm{~min}$ ). While for a conventional epoxy-amine thermoset this finding would be difficult to understand, examination of the extent of reaction of the DGEBA/DEA material demonstrates that the reaction has progressed further at the lower temperature in this time regime (e.g., compare $T=95^{\circ} \mathrm{C}$ to $T=75^{\circ} \mathrm{C}$ in Fig $5 \mathrm{~B}$ ). A less advanced reaction results in a larger average molecular weight between crosslinks that will contribute to the lower $T_{\mathrm{g}}$. Differences in the reaction mechanism over this temperature range may also contribute to molecular structure differences that affect $T_{\mathrm{g}}$. In Fig. 10.B, the $T_{\mathrm{g}}$ determined from the peak in loss modulus $G^{\prime \prime}$, [17] is compared to the DSC results. As is typical, the $G^{\prime \prime}$, measure of $T_{\mathrm{g}}$ is higher than the DSC case (by about $11^{\circ} \mathrm{C}$ in this case). However, the two results parallel each other. If the SNL $90^{\circ} \mathrm{C}$ results are assumed to represent $T_{\text {cure }}=100^{\circ} \mathrm{C}$ for short cure time, the SNL-Lundberg composite data set can be fit to

$$
T_{g}=105^{\circ} \mathrm{C}\left[1-\left(\frac{105 \mathrm{~min}}{t_{\text {cure }}}\right)^{0.4}\right] \quad \text { for } T_{\text {cure }}=100^{\circ} \mathrm{C}
$$

for $t_{\text {cure }}$, the cure time, $>200 \mathrm{~min}$. In Fig. 10.C, additional DSC results from the present study are included for $T_{\text {cure }} \leq 70^{\circ} \mathrm{C}$. Here the $T_{\mathrm{g}}$ at fixed $t_{\text {cure }}$ is seen to increase with $T_{\text {cure }}$. In Fig. 10.D, DSC results for $T_{\text {cure }} \geq 70^{\circ} \mathrm{C}$ are shown. The $T_{\mathrm{g}}$ for a given $t_{\text {cure }}$ is seen to 
decrease slightly with increasing $T_{\text {cure }}$ until it coincides with the $100^{\circ} \mathrm{C}$ line. Since we do not have extended curing results for many temperatures, it is not clear if these other high $T_{\text {cure }}$ track the $100^{\circ} \mathrm{C}$ curve to long cure time. For instance, $T_{\mathrm{g}}$ for $T_{\text {cure }}=85^{\circ} \mathrm{C}$ may level off at less than $100^{\circ} \mathrm{C}$, although the Lundberg $40^{\circ} \mathrm{C}$ results suggest that significant cure continues for $T_{\text {cure }}<T_{\mathrm{g}}$. In addition to the chemical reaction mechanisms changing with temperature, diffusion limitations will vary with temperature in the long time portion of the reaction as well. This is expected to have an effect on the time dependence of $T_{\mathrm{g}}$ for each $T_{\text {cure }}$, even if the same ultimate $T_{\mathrm{g}}$ is obtained at all $T_{\text {cure }}$.

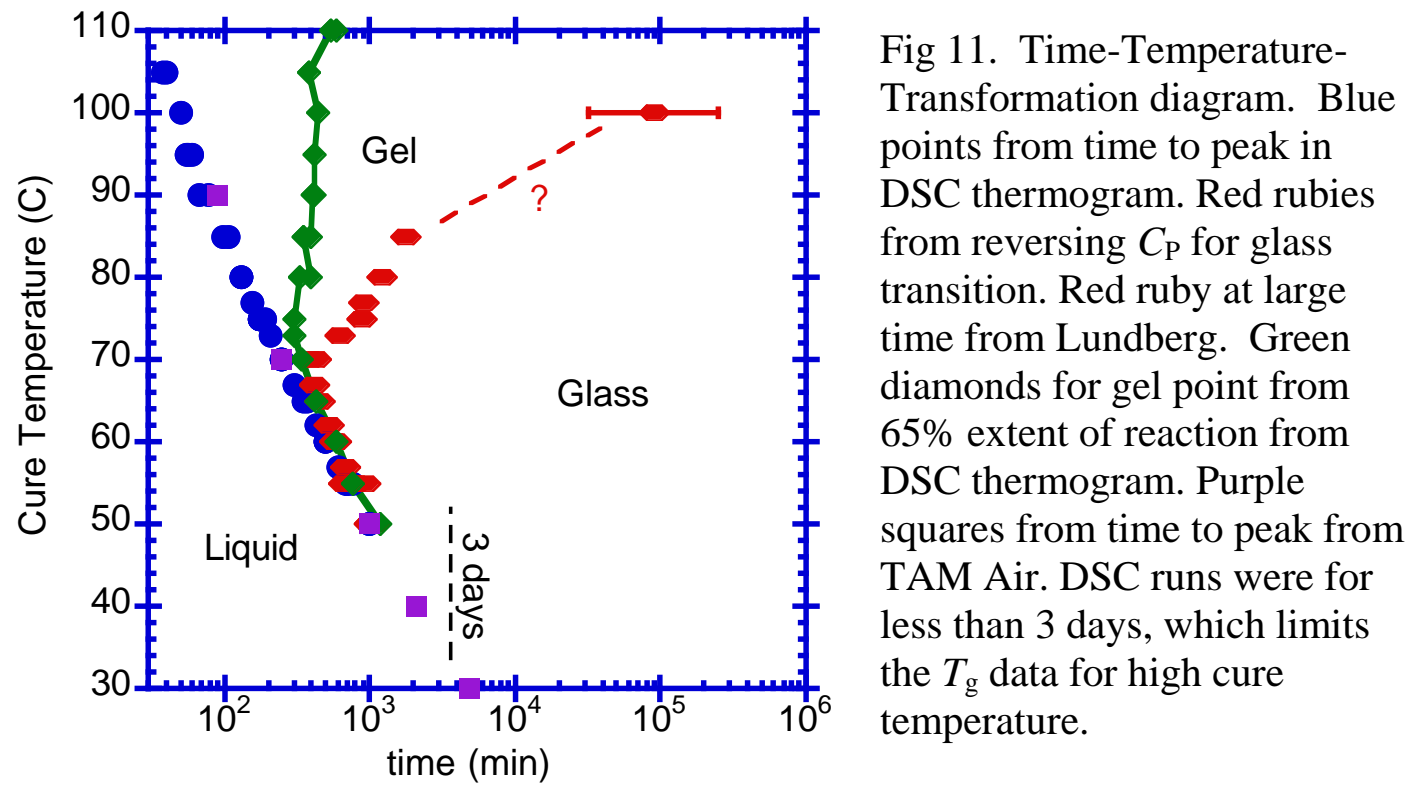

In Fig. 11, the time-temperature-transformation plot [64] for this epoxy is shown.

The circles are the times where the reaction rates are maximum at each cure temperature.

The diamonds are the gel points, which, for this system, are the times at which the extent of reaction is $65 \%$ [6]. The ruby symbols are the times where the $\operatorname{rev} C_{\mathrm{p}}$ begins to decrease and is a measure of the glass transition. The last vitrification point (at $T_{\text {cure }}$ $=100^{\circ} \mathrm{C}$ ) is from Lundberg data. Interestingly, the gel time is roughly constant for temperatures above $70^{\circ} \mathrm{C}$. This is similar to what is found [47] for the related system 
DGEBA:butanediol:benzyl dimethylamine, where gel time decreases with increasing cure temperature up to $80^{\circ} \mathrm{C}$ and then remains constant with continued increase in temperature until about $120^{\circ} \mathrm{C}$. At cure temperatures above $120^{\circ} \mathrm{C}$, the gel time increases with increasing temperature until above $140^{\circ} \mathrm{C}$ where a gel point is no longer observed [47]. The onset of increasing gel time at $120^{\circ} \mathrm{C}$ corresponds to the change in the nature of the reaction from activated (peak in rate versus time) to unactivated (no peak). This is consistent with the behavior observed in DGEBA/DEA in this work. DSC data does not resolve a peak in the DGEBA/DEA reaction rate at reaction temperatures of $T=110 \mathrm{C}$ and above. So while cure has not been investigated in detail for $T>110^{\circ} \mathrm{C}$, a similar increase in gel time may occur above a critical temperature.

\section{Conclusions}

Many of the cure behaviors seen in DGEBA/DEA have also been observed in other weak tertiary-amine cured epoxies. These behaviors include the following: (1) a non-monotonic dependence of the maximum $T_{\mathrm{g}}$ achievable on cure temperature and on amine concentration, (2) a minimum value of the gel time at high cure temperature, (3) complex reaction kinetics, and (4) an upper "stability temperature" above which the reaction slows. All of these findings provide clues to the reaction mechanisms occurring in the material, even if the mechanisms have not been directly resolved. The focus of this work was the DGEBA/DEA gelation reaction and developing a methodology to predict the progression of the reaction. The current state of understanding of the reaction follows. 
The kinetics of the DGEBA/DEA gelation reaction do not exhibit characteristics typical of more commonly employed epoxy thermosets (e.g., those cured by primary amines). Under some conditions the reaction rate decreases with increasing temperature, and the overall reaction progression is not superimposable with temperature and degree of epoxide conversion. While these findings are difficult to comprehend on their own, when they are compared with the trends from simpler model compounds (Section 2), a picture of the chemical mechanisms occurring to create the unusual kinetic behavior of DGEBA/DEA emerges. The tertiary amine from the adduct-forming reaction can initiate an anionic chain growth polymerization, with the typical initiation (Fig. 2), propagation (Fig. 3), and termination steps (Fig. 4). Both the tertiary-amine and the hydroxyl groups are essential to forming the zwitterion from an epoxide group, and this initiates the polymerization. Since the system has a high concentration of hydroxyls, proton exchange can occur, thereby forming a free alkoxide that can then attack (and bond to) another epoxide group. This then forms a crosslink between DGEBA entities. The opened epoxide group can then be protonated from a hydroxyl and the process will continue with the newly formed alkoxide. Of course, the alkoxide originating from the epoxide can also react with another epoxide in homo-polymerization. The ratio of chain transfer to homo-polymerization reactions cannot be assessed at this time and may depend on temperature and degree of cure. Chain transfer is anticipated to become more dominant as the reaction progresses due to the concentration of epoxide decreasing while that of hydroxyl stays constant. The zwitterion intermediate also becomes more sterically hindered as the reaction proceeds, which can affect reaction rate with degree of conversion. 
Similar zwitterion complexes in other systems have been noted to destabilize at elevated temperature and reduce the reaction rate. The reaction becomes dominated by the much slower polymerization resulting from simple epoxide accelerated by alcohols and by the non-ionic, epoxy-hydroxyl addition reactions (Fig. 1). The results presented here suggest the upper stability temperature for the zwitterion complex in DGEBA/DEA is $70^{\circ} \mathrm{C}$, although remnants of the anionic polymerization can be seen above $70^{\circ} \mathrm{C}$ in the small reaction peak that continues to exist.

The polymerization mechanism of DGEBA/DEA drives how the material evolves during the reaction process and the interplay of material evolution, history and constraint will ultimately determine how stress develops in the material during manufacturing of encapsulated devices. Understanding and predicting the reaction process, both the chemical mechanism and the rate at which it occurs, is a key first step in developing tools to optimize manufacturing stress. The current work illustrates how difficult this first step is.

Looking forward along the path to achieve predictive tools, let us consider the possibilities of modeling the kinetic behavior of the gelation reaction in order of increasing complexity. First, let us examine whether the rate can be expressed as a product of an Arrhenius factor times a function, $f(\alpha)$, of the extent of epoxide conversion. Here, it is not assumed that $f(\alpha)$ is a simple product of concentrations, but, instead, can be of arbitrary complexity (e.g., a Kamal form). We show that this expression is insufficient due to (1) the failure of a shift factor reduction of $\alpha$ vs. $\log (t)$, (Fig. 5) and (2) the nonArrhenius nature of the reaction rate peak height (Fig. 8). 
Second, let us contemplate whether the rate can be expressed as an arbitrary function of temperature, $T$, times a function of $\alpha$ alone in so-called "non-Arrhenius" kinetics [65]. We show that this cannot be the case because (1) the shape of the $\alpha$ vs. $\log (t)$ changes with temperature so that the curves at high temperature are not superimposable on curves at low temperature with a simple, temperature dependent, multiplier on time (Fig. 5) and (2) the curves of peak height and peak location versus $1 / \mathrm{T}$ do not parallel each other (Fig. 8).

Third, let us ask whether the rate can be expressed as a combined function of $T$ and $\alpha: f(T, \alpha)$. Before discussing why this also cannot be the case, it should be appreciated that this extreme functional generality can describe experimental results if only isothermal experiments are considered. Since the functional form can change with temperature (for instance, $n$ and $m$ in the Kamal equation would depend on temperature), it is not necessary that $\alpha$ vs. $\log (t)$ curves (Fig. 5) superimpose nor that peak heights and peak locations have any consistent relation to each other (Fig. 8). The engineering appeal of this level of modeling should be appreciated. However, epoxies are not typically cured isothermally, but, instead, are subjected to a more complicated thermal history that serves to limit exothermic heating, filler settling, and/or the build-up of internal stresses [66]. Thus, as has been observed by others [61], having a function that can predict the reaction process throughout its thermal history is a necessary tool for cure schedule design.

Since the $f(T, \alpha)$ approach neglects the details of the reaction mechanism, it can fail to capture behavior that it has not been trained for. For instance, consider the zwitterion/alkoxide-anion intermediates in the DGEBA/DEA reaction. The anion concentration is sensitive to temperature but cannot respond immediately to stimuli that 
alter its equilibrium condition. Consequently, the anion concentration after a temperature up-jump will retain its low temperature value for some time and the reaction rate may vary considerably from that of an isothermal reaction at the same $T$ and $\alpha$. Our preliminary experiments with this history show large differences (as much as an order of magnitude) in reaction rates between temperature jumps and isothermal reactions. We are working to quantify these differences and interpret them in terms of the proposed reaction mechanisms discussed in the present study.

The reaction mechanism discussed in detail in this paper suggests that the rate of epoxide reaction should be treated with an even more general functional form. If the concentrations of the intermediates in the various sub-reactions (Fig.1-4) are denoted as $X_{1}, X_{2}, \ldots$, then the overall rate can be modeled as $f\left(T, \alpha, X_{1}, X_{2}, \ldots\right)$. Indeed, this approach has been suggested by Fernandez-Francos [7] and, earlier, by Laird and Parker [10]. Of course, the number of parameters that need to be evaluated is formidable (several dozen in the Fernandez-Francos case). However, without specific consideration of at least some of these dilute intermediates in the reaction sequence, a model of the reaction kinetics applicable to all time/temperature cure histories is impossible.

In a future study, more details of our DSC, IR and microcalorimetry studies of DGEBA/DEA will be presented along with kinetic modeling of isothermal cure. Model epoxy systems that permit tracking of the major reaction intermediates are also under investigation. 


\section{Acknowledgements}

Sandia National Laboratories is a multi-mission laboratory managed and operated by Sandia Corporation, a wholly owned subsidiary of Lockheed Martin Corporation, for the U.S. Department of Energy’s National Nuclear Security Administration under contract DE-AC04-94AL85000.

\section{References}

1. Quant A. A Low Density Potting Compound. Sandia Corp., 1961.

2. Spencer JB. Cure Shrinkage of Casting Resins. SAND SCDC 2568: Sandia Corp., 1962.

3. Lee H and Neville K. Handbook of Epoxy Resins: McGraw-Hill, 1967.

4. Sanders, R., Private Communication, National Security Campus, 2015.

5. Shechter L, Wynstra J, and Kurkjy RP. Industrial and Engineering Chemistry 1956;48(1):94-97.

6. $\quad$ Adolf D and Chambers R. Polymer 1997;38(21):5481-5490.

7. Fernandez-Francos X. European Polymer Journal 2014;55:35-47.

8. Rozenberg BA. Advances in Polymer Science 1986;75:113-165.

9. Shechter L and Wynstra J. Industrial and Engineering Chemistry 1956;48(1):86-

93.

10. Laird RM and Parker RE. Journal of the Chemical Society B-Physical Organic 1969(9):1062-1068.

11. St. John NA and George GA. Progress in Polymer Science 1994;19(5):755-795.

12. Lundberg CV. Industrial \& Engineering Chemistry Product Research and Development 1980;19(3):319-326. 
13. Adolf D. Coefficients of Thermal Expansion of Common Encapsulants SAND Report, vol. SAND88-0777, 1988.

14. Adolf D. Measurement Techniques for Evaluating Encapsulant Thermophysical Properties During Cure. SAND Report, vol. SAND96-1458, 1996.

15. Adolf DB, Stavig ME, and Berry RS. SAND Report 2007;SAND2007-2287.

16. Wischmann KB and Thomas EV. An Evaluation of the Effects of Varying Composition and Processing on Several Encapsulating Resins SAND Report, vol. SAND89-1023, 1991.

17. Adolf D. Sandia Polymer-Web http://www.sandia.gov/polymerproperties/828_DEA.html, 2010.

18. Kamal MR and Sourour S. Polymer Engineering and Science 1973;13(1):59-64.

19. Kamal MR. Polymer Engineering \& Science 1974;14(3):231-239.

20. Sourour S and Kamal MR. Thermochimica Acta 1976;14(1-2):41-59.

21. Adolf, D.B., Private Communication 2010.

22. Adolf D and Martin JE. Macromolecules 1990;23(15):3700.

23. Adolf D and Martin JE. Macromolecules 1991;24(25):6721-6724.

24. Adolf D, Martin JE, and Wilcoxon JP. Macromolecules 1990;23(2):527.

25. Adolf DB, Martin JE, Chambers RS, Burchett SN, and Guess TR. Journal of Materials Research 1998;13(3):530-550.

26. Jordan JL, Foley JR, and Siviour CR. Mechanics of Time-Dependent Materials 2008;12(3):249-272. 
27. Jordan JL, White B, Spowart JE, Richards DW, and Thadhani NN. Conference: 20072007 SEM Annual Conference \& Exposition on Experimental and Applied Mechanics 2007.

28. White BJ. Thesis (Georgia Institute of Technology) 2011.

29. Weeks TS, Adolf D, and McCoy JD. Macromolecules 1999;32(6):1918.

30. Adolf DB, Chambers RS, and Caruthers JM. Polymer 2004;45:4599.

31. Adolf DB, Chambers RS, and Neidigk MA. Polymer 2009;50(17):4257-4269.

32. Adolf DB, Chambers RS, Elisberg B, Stavig M, and Ruff M. Journal of Applied Polymer Science 2011;119(4):2143-2152.

33. Adolf DB, Chambers RS, Stavig ME, and Kawaguchi ST. Journal of Adhesion 2006;82(1):63-92.

34. Adolf DB, Stavig ME, Kawaguchi S, and Chambers RS. Journal of Adhesion 2007;83(1-3):85-104.

35. Adolf DB, Chambers RS, Hance B, and Elisberg B. Journal of Adhesion 2010;86(11):1111-1131.

36. Adolf D, Strommen R, and Johnson H. Viscosities of Epoxy Encapsulants. SAND Report, vol. SAND97-2631, 1997.

37. Cheung MF, Garrett DL, Parsons J, and Vanoene H. Industrial \& Engineering Chemistry Product Research and Development 1986;25(2):296-302.

38. Doszlop S, Vargha V, and Horkay F. Periodica Polytechnica-Chemical Engineering 1978;22(3):253-275.

39. Shechter L, Wynstra J, and Kurkjy RP. Industrial and Engineering Chemistry 1957;49(7):1107. 
40. Heckert WW and Mack E. Journal of the American Chemical Society 1929;51(9):2706-2717.

41. Anderson HC. Analytical Chemistry 1960;32(12):1592-1595.

42. Remiro PM, Cortazar MM, and Calahorra ME. Journal of Materials Science 1999;34(11):2627-2633.

43. Remiro PM, Cortazar M, Calahorra E, and Calafel MM. Polymer Degradation and Stability 2002;78(1):83-93.

44. Bowen DO and Whiteside RC. Advances in Chemistry Series 1970;92:48-59.

45. Ikeda I, Mitsumoto S, Yamada Y, and Suzuki K. Polymer International $1991 ; 26(2): 115-119$.

46. Dell'Erba IE and Williams RJJ. Polymer Engineering and Science 2006;46(3):351-359.

47. Tanzer W, Reinhardt S, and Fedtke M. Polymer 1993;34(16):3520-3525.

48. Tanzer W, Szesztay M, Laszlohedvig Z, and Fedtke M. Polymer Bulletin 1988;20(2):189-194.

49. Wolff D, Schlothauer K, Tanzer W, Fedtke M, and Spevacek J. Polymer 1991;32(11):1957-1960.

50. Heise MS and Martin GC. Macromolecules 1989;22(1):99-104.

51. St. John NA and George GA. Polymer 1992;33(13):2679-2688.

52. Podzimek S, Dobas I, and Kubin M. Journal of Applied Polymer Science 1992;44(9):1601-1605.

53. Hagnauer G. Army Materials and Mechanics Research Division 1979;AMMRCTR-79-59. 
54. Sbirrazzuoli N, Mititelu-Mija A, Vincent L, and Alzina C. Thermochimica Acta 2006;447(2):167-177.

55. Celina MC, Giron NH, and Rojo MR. Polymer 2012;53(20):4461-4471.

56. Dannenberg H. SPE Transactions 1963;January:78-88.

57. Duemichen E, Javdanitehran M, Erdmann M, Trappe V, Sturm H, Braun U, and Ziegmann G. Thermochimica Acta 2015;616:49-60.

58. Pandita SD, Wang LW, Mahendran RS, Machavaram VR, Irfan MS, Harris D, and Fernando GF. Thermochimica Acta 2012;543:9-17.

59. Wadso L. Cement and Concrete Research 2010;40:1129.

60. Wadso L. TA Instruments Application Note 2007;M135.

61. Fernandez-Francos X, Cook WD, Serra A, Ramis X, Liang GG, and Salla JM. Polymer 2010;51(1):26-34.

62. Thomas LC. TA Instruments 2005;TP007.

63. Van Assche G, Van Hemelrijck A, Rahier H, and Van Mele B. Thermochimica Acta 1997;305:317-334.

64. Enns JB and Gillham JK. Journal of Applied Polymer Science 1983;28(8):25672591.

65. Smith IWM. Chemical Society Reviews 2008;37:812.

66. Kropka JM, Stavig ME, and Jaramillo R. Residual Stress Developed During the Cure of Thermosetting Polymers: Optimizing Cure Schedule to Minimize Stress. SAND Report, vol. SAND2016-5543, 2016. 


\section{Graphical Abstract}
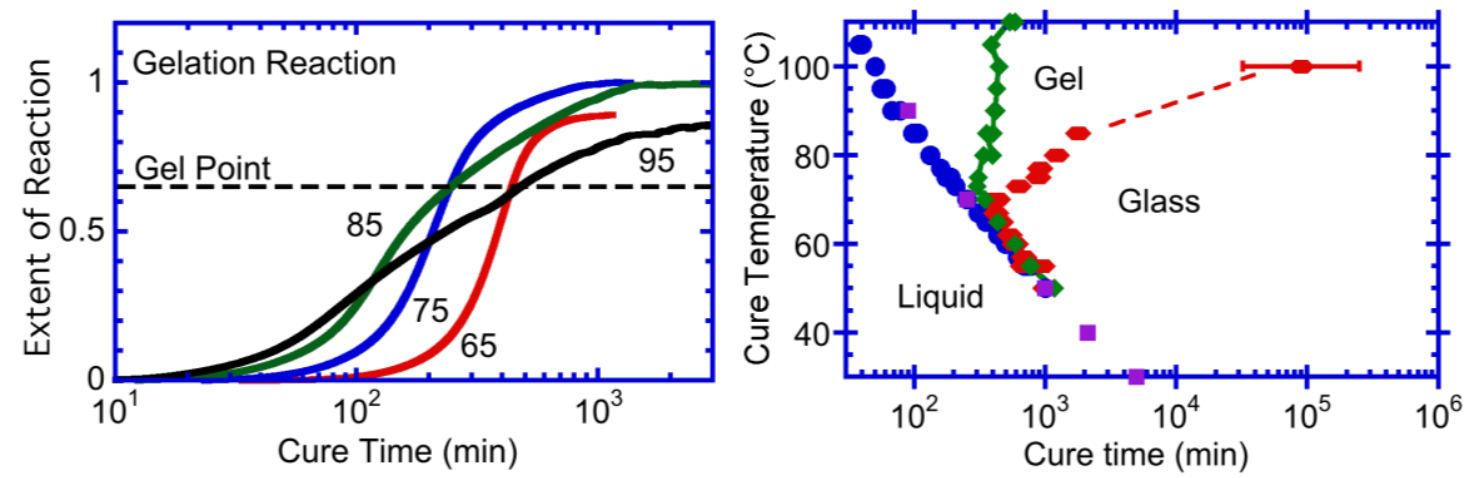